Article

\title{
Influence of nickel(II) oxide surface magnetism on molecule adsorption: A first-principles study
}

\author{
Chuan-Qi Huang a,b, Wei-Xue Li a,b,c,* \\ a State Key Laboratory of Catalysis, Dalian Institute of Chemical Physics, Chinese Academic of Sciences, Dalian 116023, Liaoning, China \\ b University of Chinese Academy of Sciences, Beijing 100049, China \\ c Department of Chemical Physics, College of Chemistry and Materials Science, iChEM, CAS Center for Excellence in Nanoscience, Hefei National Laboratory \\ for Physical Sciences at the Microscale, University of Science and Technology of China, Hefei 230026, Anhui, China
}

\section{A R T I C L E I N F O}

\section{Article history:}

Received 27 May 2017

Accepted 26 June 2017

Published 5 October 2017

\section{Keywords:}

Magnetism

Surface orientation

Molecule adsorption

First-principles theory

Electronic structure

\begin{abstract}
A B S T R A C T
The influence of the magnetism of transition metal oxide, nickel(II) oxide (NiO), on its surface reactivity and the dependence of surface reactivity on surface orientation and reactant magnetism were studied by density functional theory plus U calculations. We considered five different antiferromagnetically ordered structures and one ferromagnetically ordered structure, $\mathrm{NiO}(001)$ and $\mathrm{Ni}(011)$ surfaces, paramagnetic molecule NO, and nonparamagnetic molecule CO. The calculations showed that the dependence of surface energies on magnetism was modest, ranging from 49 to 54 $\mathrm{meV} / \AA^{2}$ for $\mathrm{NiO}(001)$ and from 162 to $172 \mathrm{meV} / \AA^{2}$ for $\mathrm{NiO}(011)$. On NiO(001), both molecules preferred the top site of the $\mathrm{Ni}$ cation exclusively for all $\mathrm{NiO}$ magnetic structures considered, and calculated adsorption energies ranged from -0.33 to $-0.37 \mathrm{eV}$ for $\mathrm{CO}$ and from -0.42 to $-0.46 \mathrm{eV}$ for NO. On NiO(011), both molecules preferred the bridge site of two Ni cations irrespective of the NiO magnetism. It was found that rather than the long-range magnetism of bulk NiO, the local magnetic order of two coordinated $\mathrm{Ni}$ cations binding to the adsorbed molecule had a pronounced influence on adsorption. The calculated NO adsorption energy at the ( $\uparrow \downarrow)$ bridge sites ranged from -0.99 to $-1.05 \mathrm{eV}$, and become stronger at the ( $\uparrow)$ bridge sites with values of -1.21 to $-1.30 \mathrm{eV}$. For CO, although the calculated adsorption energies at the ( $\uparrow \downarrow)$ bridge sites $(-0.73$ to $-0.75 \mathrm{eV})$ were very close to those at the $(\uparrow \uparrow)$ bridge sites $(-0.71$ to $-0.72 \mathrm{eV}$ ), their electron hybridizations were very different. The present work highlights the importance of the local magnetic order of transition metal oxides on molecular adsorption at multi-fold sites.
\end{abstract}

(c) 2017, Dalian Institute of Chemical Physics, Chinese Academy of Sciences. Published by Elsevier B.V. All rights reserved.

\section{Introduction}

Transition metal oxide (TMO) surfaces currently have a wide range of applications in energy and environmental science, such as catalysts for clean energy conversion, cleanup of air pollutants, and sensors for chemical and biomedical devices $[1,2]$. Understanding the surface chemistry and struc- ture-activity relationship of TMOs is therefore important for the further development of these applications [3]. In particular, $3 d$ TMOs are notable because of their involved spin states and magnetism, which is sensitive to surface orientation and particle size [4-7]. For instance, the spin states of Co ions (rather than number of $3 d$ electrons) in perovskite oxides play a critical role in their oxygen evolution activity [8]. In addition to

\footnotetext{
*Corresponding author. Tel: +86-551-63600650; E-mail: wxli70@ustc.edu.cn

This work was supported by the National Natural Science Foundation of China (91645202), the National Key R\&D Program of China (2017YFB602205), the National Basic Research Program of China (2013CB834603), and the Frontier Science Key Project of Chinese Academy of Sciences (QYZDJ-SSW-SLH054).

DOI: 10.1016/S1872-2067(17)62883-3 | http://www.sciencedirect.com/science/journal/18722067 | Chin. J. Catal., Vol. 38, No. 10, October 2017
} 
oxides, the spin states of molecules such as $\mathrm{O}_{2}$ influence their corresponding dissociation activity on oxides [9] and even simple metal surfaces [10]. Magnetism can be induced in metal oxides that are paramagnetic in bulk by surface adsorption and reaction $[11,12]$. It is therefore interesting to study the influence of the spin states and magnetism of oxides on their surface chemistry.

Late $3 d$ transition metal monoxides $(\mathrm{MnO}, \mathrm{FeO}, \mathrm{CoO}$, and $\mathrm{NiO})$ with cubic rock salt structure $(\mathrm{Fm} \overline{3} \mathrm{~m})[13,14]$ are of particular importance in the study of antiferromagnetic (AFM) TMOs, and are often considered as model AFM systems. Besides their relatively high Neel temperature $\left(T_{\mathrm{N}}\right)$ and chemical stability, their large band gap $\left(E_{\mathrm{G}}\right)$ and insulating electronic structure allow their magnetic properties to be accurately described in terms of magnetic moments localized on transition metal cations $[15,16]$. The anisotropic interaction between neighboring magnetic moments leads to long-range magnetic ordering, known as type-2 antiferromagnetism (AFM2), below $T_{\mathrm{N}}$ [17-20] and stacking of ferromagnetic (FM) (111) planes with opposite spin directions in adjacent layers, as identified by neutron diffraction [21]. Using magnetic exchange force microscopy, the magnetic order of surface nickel ions on the $\mathrm{NiO}(001)$ surface has been measured directly in real space [22-26]. Despite the definite AFM order of magnetic ions in the perfect bulk crystal below $T_{\mathrm{N}}$, the ordering of magnetic ions on the surface can be changed under different conditions. For example, by engineering defects in the lattice of AFM NiO, a FM ordering dislocation can be introduced [27]. When the size of AFM NiO decreases to the nanoscale, the resulting decrease of coordination and lattice distortion can drive the phase transition to a FM-like phase $[27,28]$.

The magnetism of metal ions in late $3 d$ TMOs originates from their partially filled $3 d$ states, which are famous for their highly correlated nature [29]. It remains challenging to accurately describe strongly localized and correlated $d$ electrons using standard density functional theory (DFT) approaches such as the local density approximation (LDA) or generalized gradient approximation (GGA) [30,31]. Both the LDA and GGA often fail to predict $E_{\mathrm{G}}$ of these TMOs [32]. For instance, both $\mathrm{CoO}$ and $\mathrm{FeO}$ were predicted to be metallic. Although $\mathrm{NiO}$ and $\mathrm{MnO}$ were predicted to have $E_{\mathrm{G}}$, the calculated values were severely underestimated [33]. Nevertheless, $E_{\mathrm{G}}$ of these materials can be opened in calculations by adding a Hubbard U term describing the strong on-site Coulomb repulsion to the LDA or GGA (DFT+U) [34,35]. Compared to higher-level theories such as the hybrid functional or many-body perturbation $[31,36]$, $\mathrm{DFT}+\mathrm{U}$ can substantially improve the calculation accuracy without increasing the computational cost, as demonstrated for the adsorption of $\mathrm{CO}$ and $\mathrm{NO}$ on $\mathrm{NiO}(001)[37,38]$. Simulation of water dissociative adsorption on $\mathrm{NiO}(111)$ was reported recently, and the calculation was found to be fairly insensitive to the choice of the DFT $+U$ functional [39].

Chemically equivalent oxide surfaces may become inequivalent when considering the different symmetry of various long-range magnetisms. Because surface chemistry is largely decided by local environment (geometry and composition), it is currently unclear how the different magnetisms affect surface chemistry. Furthermore, the influence of different surfaces on magnetisms is still unknown. This influence may be mediated by reactants with different spin and/or magnetic moments. To clarify these issues, here $\mathrm{NiO}$ as a model system is studied by the GGA $+U$ method. A number of magnetic phases, including AFM1, AFM2, AFM3, AFM4, AFM5, and FM, are considered. $\mathrm{NiO}(001)$ and $\mathrm{NiO}(110)$ surfaces are used to study the sensitivity of these magnetic phases to structure. While $\mathrm{CO}$ and NO adsorbed on $\mathrm{NiO}(001)$ of AFM2 has been studied to verify the $\mathrm{DFT}+\mathrm{U}$ scheme treatment for strongly correlated systems $[37,38]$, here we use the adsorption of paramagnetic molecule NO and nonparamagnetic molecule CO to probe the influence of magnetism on molecule adsorption by $\mathrm{NiO}$ surfaces.

\section{Computational details}

DFT calculations were performed with the Vienna ab initio simulation package (VASP) [40] based on the projected augmented wave (PAW) method [41,42]. The spin-polarized Perdew Burke Ernzerhof (PBE) [43] exchange-correlation functional and on-site Coulomb repulsion $\mathrm{U}$ term for $d$ electrons in the spirit of Hubbard according to Dudarev's approach [35] were used to describe electron exchange and correlation. An effective $\mathrm{U}$ of $5.3 \mathrm{eV}$ for Ni was used throughout the present work, because it could reproduce well bulk properties and $\mathrm{CO} / \mathrm{NO}$ adsorption on $\mathrm{NiO}(001)$ surfaces [37].

Because partially occupied $d$ orbitals are strongly localized at $\mathrm{Ni}^{2+}$, a net spin magnetic moment was assigned to each $\mathrm{Ni}^{2+}$. For the cubic sublattice of magnetic ions, all magnetic ions having parallel spin means there is FM order (Figure 1(a)). In

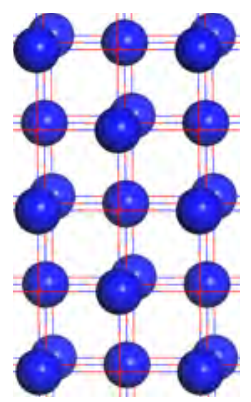

(a) FM

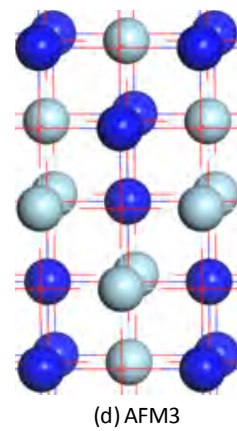

$p=2, \mathbf{G}=(201)$

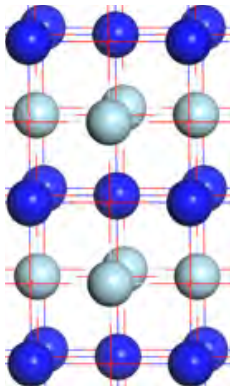

(b) AFM1 $p=1, \mathbf{G}=(001)$

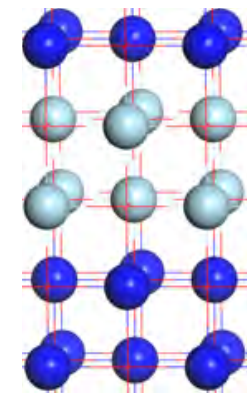

(e) AFM4 $p=2, \mathbf{G}=(001)$

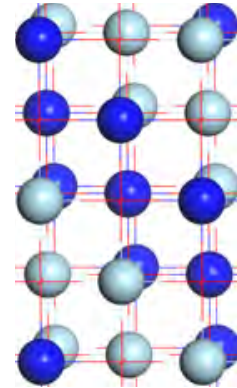

(c) AFM2 $p=1, \mathbf{G}=(111)$

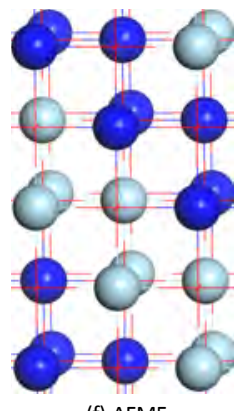

(f) AFM5 $p=2, \mathbf{G}=(101)$
Fig. 1. Schematic illustration of NiO ferromagnetism FM (a), antiferromagnetism AFM1 (b), AFM2 (c), AFM3 (d), AFM4 (e) and AFM5 (f). Line cross points represent $\mathrm{O}$, blue balls represent $\mathrm{Ni}$ spin up, and white balls represent Ni spin down. 
contrast, the series of common AFM configurations of $\mathrm{Ni}^{2+}$ AFM1-AFM5 (as shown in Figure 1(b-f)) can be described as oppositely stacked FM layers in direction $G$ with super lattice periodicity $p$ in which $\mathrm{Ni}^{2+}$ maintain parallel spin within $p$ layers [44]. Below $T_{\mathrm{N}}=523 \mathrm{~K}$, the ground-state magnetic configuration of $\mathrm{NiO}$ is AFM2 [21]. We considered AFM1-AFM5 and FM magnetic order as a starting point to construct surfaces with different surface magnetic order by truncation of bulk NiO.

Four layers of an $\mathrm{NiO}(001)$ slab $(2 \sqrt{2} \times 2 \sqrt{2})$ surface supercell and five layers of an $\mathrm{NiO}(011)$ slab $(4 \times 4)$ surface supercell were used to model the adsorption of molecules on $\mathrm{NiO}(001)$ and $\mathrm{NiO}(011)$ surfaces, respectively. Slabs were separated by $12 \AA$ of vacuum with the bottom two layers fixed at the bulk truncated structure, and dipole correction perpendicular to each slab was imposed. The layer thickness and vacuum size were found to converge for adsorption of CO/NO on AFM2. Surface energy was evaluated with symmetric slabs of the minimum surface cell for each surface until they converged to less than $1 \mathrm{meV} / \AA^{2}$ with respect to slab thickness. A plane wave cutoff of $400 \mathrm{eV}$ and k-point grids of $(4 \times 4 \times 1)$ for $\mathrm{NiO}(001)$ $(2 \sqrt{2} \times 2 \sqrt{2})$ and $(3 \times 2 \times 1)$ for $\mathrm{NiO}(011)-(2 \times 4)$ were used. Geometrical optimization was performed until the force on relaxed atoms was less than $0.02 \mathrm{eV} / \AA$.

\section{Results and discussion}

\subsection{NiO bulk}

Table 1 lists the optimized equilibrium lattice constant, energy difference per $\mathrm{NiO}$ formula with respect to the lowest energy state (AFM2), localized magnetic moment on $\mathrm{Ni}$, and band gap for the various magnetic phases considered. The energetically most favorable long-range magnetic phase is AFM2, which is consistent with the structure of $\mathrm{NiO}$ below $T_{\mathrm{N}}$ determined by neutron diffraction. The energy difference between different magnetic phases can be as large as $102 \mathrm{meV} / \mathrm{NiO}$. AFM2 has the smallest lattice constant ( $a=4.19 \AA$ ) and magnetic moment of $\mathrm{Ni}\left(m=1.71 \mu_{\mathrm{B}}\right)$, but the largest $E_{\mathrm{G}}$ of $3.25 \mathrm{eV}$ for the magnetic phases. The present work agrees well with the results of a previous SGGA+U calculation ( $a=4.20 \AA, m=1.72 \mu_{\mathrm{B}}, E_{\mathrm{G}}=3.2 \mathrm{eV}$ ) [37]. For the other AFM phases, the lattice constant and magnetic moment increase by $0.02 \AA$ and $0.10 \mu_{\text {B }}$ at most, respectively, but $E_{\mathrm{G}}$ decreases by $1.16 \mathrm{eV}$. It is clear that the lower the energy of the magnetic phase, the smaller the lattice constant

\section{Table 1}

Energy difference per $\mathrm{NiO}$ formula with respect to the lowest state (AFM2) $(\Delta E)$, equilibrium lattice constant $(a)$, localized magnetic moment on $\mathrm{Ni}(M)$, and energy band gap $\left(E_{\mathrm{G}}\right)$ of various magnetism phases.

\begin{tabular}{lrrrc}
\hline & $\Delta E / \mathrm{meV}$ & $a / \AA$ & $M / \mu_{\mathrm{B}}$ & $E_{\mathrm{G}} / \mathrm{eV}$ \\
\hline AFM1 & 101 & 4.21 & 1.81 & 2.20 \\
AFM2 & 0 & 4.19 & 1.71 & 3.25 \\
AFM3 & 65 & 4.20 & 1.77 & 2.51 \\
AFM4 & 61 & 4.20 & 1.77 & 2.26 \\
AFM5 & 30 & 4.19 & 1.74 & 2.88 \\
FM & 91 & 4.21 & 1.80 & 2.09 \\
\hline
\end{tabular}

and magnetic moment and the larger the $E_{\mathrm{G}}$. These trends originate from the superexchange interaction of the second nearest neighbor $(\mathrm{NN}) \mathrm{Ni}^{2+}$, as rationalized in an earlier theory for rock salt transition metal monoxides [33,45].

To understand the origin of the AFM behavior of NiO, we fitted the calculated energy in Table 1 to the Ising model of magnetic moment interaction [19]. The fitting result gives $i$-th NN magnetic moment exchange pair interactions $J_{i}(i=1,2,3$, and 4) of $0.71,-15.58,-0.24$, and $0.07 \mathrm{meV}$, respectively. This means that the second $\mathrm{NN}$ interaction $\left.\mathrm{U}_{2}\right)$ is the dominant interaction and the negative value indicates the preference for AFM order, similar to the behavior of $\mathrm{CoO}$ and $\mathrm{MnO}[18,19]$. Because $J_{1}, J_{3}$, and $J_{4}$ are much smaller than $J_{2}$, the number of second NN pairs determines the relative stability of the various AFM phases. For AFM2, all the second NN pairs are antiparallel, so it is energetically the most favorable state of NiO.

In this work, a Ni atom with an upward (or positive) magnetic moment $(\uparrow)$ means that the electron population of the spin-up component is larger than that of the spin-down, whereas a $\mathrm{Ni}$ atom with a downward (or negative) magnetic moment $(\downarrow)$ means that the electron population of the spin-down component is larger than that of the spin-up. The spin-resolved density of states (SDOS) of $\mathrm{Ni}(\uparrow)$ in bulk NiO-AFM2 is illustrated in Figure 2. For the $3 d_{x y, y z, x z}\left(\mathrm{t}_{2 \mathrm{~g}}\right)$ band, both the spin-up and spin-down components are distributed in the valence band. Compared with the spin-up component, the electrons in the spin-down component mainly populate the upper/top part of the valence band. For the $3 d_{x^{2}-y^{2}, z^{2}}\left(\mathrm{e}_{\mathrm{g}}\right)$ band, the marked exchange splitting causes the $e_{g}$ states to be well separated (by $\sim 9.69 \mathrm{eV}$ ). In particular, the spin-down components are distributed in the conduction band. Most of the spin-up components are distributed in the lower part of the valence band, and a small amount are distributed close to the top of the valence band. The gap between the valence band maximum (VBM) and conduction band minimum (CBM) of the $\mathrm{Ni} 3 d$ band is $3.23 \mathrm{eV}$, which is nearly same with as the $E_{\mathrm{G}}$ of bulk $\mathrm{NiO}(3.25 \mathrm{eV})$. For $\mathrm{Ni}(\downarrow)$, the corresponding components are simply reversed. As shown below, these features are essential for the hybridization between $\mathrm{Ni}$ and $\mathrm{CO} / \mathrm{NO}$ molecules.

\section{2. $\mathrm{NiO}(001)$}

\subsubsection{Surface properties}

For rock salt crystals, the (001) plane is chemically equivalent with (010), (100), $(00 \overline{1}),(0 \overline{1} 0)$, and ( $\overline{1} 00)$ : all belong to the $\{001\}$ plane family, and the corresponding primitive cell is $(1 \times 1)$. A long-range magnetic phase lowers the corresponding symmetry and decreases the degeneracy of the $\{001\}$ plane family. The nonequivalent planes depended on the long-range magnetic phase (AFM1-AFM5), as classified in Table 2 and plotted in Figure 3. Each of AFM1, AFM3, AFM4, and AFM5 had two nonequivalent planes, whereas AFM2 had only one nonequivalent plane. This led to nine nonequivalent surfaces with different primitive cells, although they are all chemically equivalent.

Taking AFM1-(100) (Figure 3(b)) as an example, the magnetic moments of the first NN Ni pair are exclusively antiparal- 

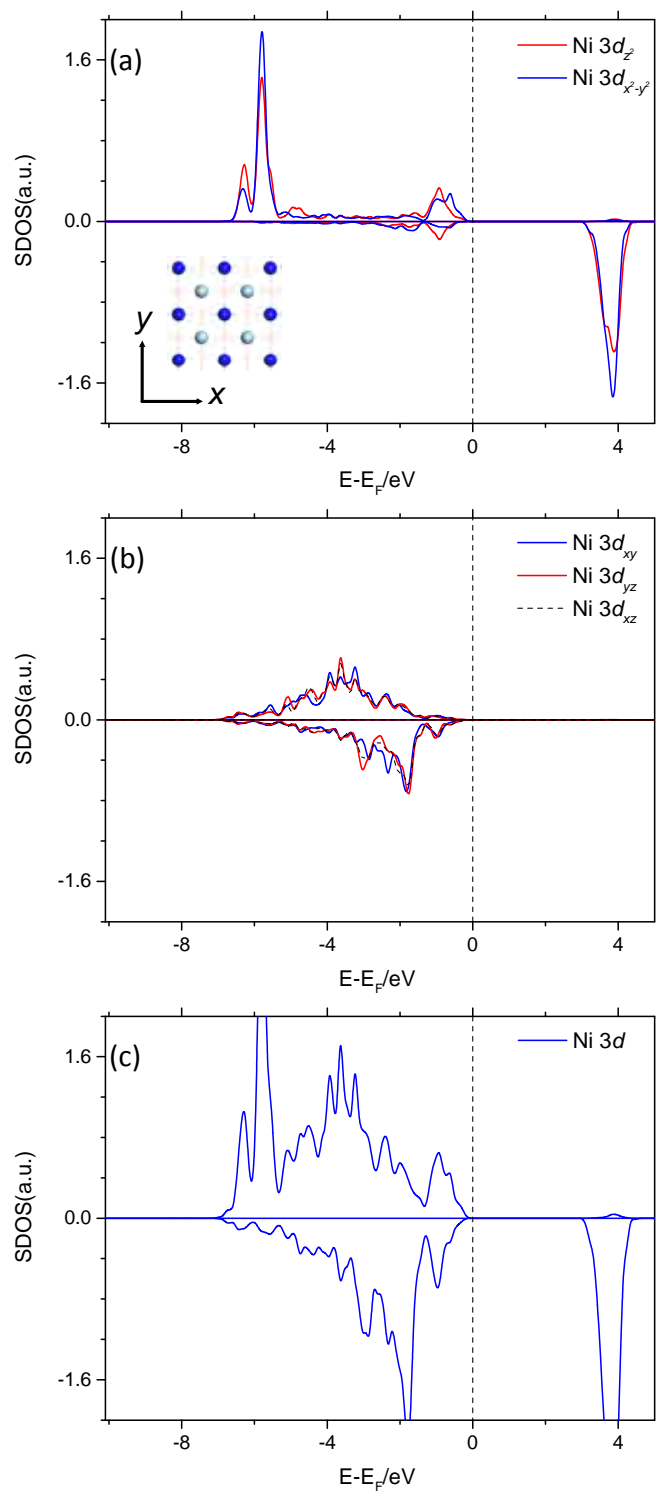

Fig. 2. Spin-resolved projected density of states (SDOS) for Ni in bulk AFM2 NiO. (a) SDOS projected onto Ni $3 d_{z^{2}}, 3 d_{x^{2}-y^{2}}$; (b) SDOS projected onto Ni $3 d_{x y}, 3 d_{y z}, 3 d_{x z}$; (c) Total SDOS of Ni $3 d$. The reference coordinates for DOS projection is shown in inset of (a), where $x$-axis represents for [100] direction and $y$-axis for [010] direction.

lel $(\uparrow \downarrow)$. Similar behavior was found for AFM3-(001) (Figure 3(d)). In contrast, for AFM1-(001) (Figure 3(a)) and AFM4-(001) (Figure 3(f)), the magnetic moments of the first NN Ni pair are exclusively parallel $(\uparrow \uparrow)$. For the remaining five surfaces shown in Figure 3, both the $(\uparrow \downarrow)$ and $(\uparrow \uparrow)$ configurations coexist in the first NN Ni pairs, forming different surface magnetism patterns. The different local magnetic pairs along with their long-range magnetic phases provide a good playground to investigate the influence of magnetism on surface properties. Figure 4 plots the SDOS of a surface Ni atom ( $\uparrow$ ) from AFM2-(001). The overall features remain the same as that of AFM2 bulk (Figure 2). The main difference is the gap between the VBM and CBM of the Ni $3 d$ band, which decreases from the bulk value of 3.23 to $2.81 \mathrm{eV}$.

The calculated surface energies are presented in Table 2 .

\section{Table 2}

Nonequivalent surfaces of rock salt $\mathrm{NiO}\{001\}$ family taking into account of magnetism, though in each column the surfaces remain equivalent. Corresponding surface energy $\gamma\left(\mathrm{meV} / \AA^{2}\right)$ is given, and as reference for $\mathrm{FM}(001), \gamma=50 \mathrm{meV} / \AA^{2}$.

\begin{tabular}{|c|c|c|c|c|c|c|c|c|}
\hline \multicolumn{2}{|c|}{ AFM1 } & AFM2 & \multicolumn{2}{|c|}{ AFM3 } & \multicolumn{2}{|c|}{ AFM4 } & \multicolumn{2}{|c|}{ AFM5 } \\
\hline 49 & 50 & 54 & 54 & 51 & 54 & 52 & 52 & 54 \\
\hline (001) & (100) & (001) & (001) & (010) & (001) & (010) & (001) & (010) \\
\hline$(00 \overline{1})$ & $(\overline{1} 00)$ & $(00 \overline{1})$ & $(00 \overline{1})$ & $(0 \overline{1} 0)$ & $(00 \overline{1})$ & $(0 \overline{1} 0)$ & $(00 \overline{1})$ & $(0 \overline{1} 0)$ \\
\hline & (010) & $(010)$ & & (100) & & (100) & (100) & \\
\hline & $(0 \overline{1} 0)$ & $(0 \overline{1} 0)$ & & $(\overline{1} 00)$ & & $(\overline{1} 00)$ & $(\overline{1} 00)$ & \\
\hline & & (100) & & & & & & \\
\hline & & $(\overline{1} 00)$ & & & & & & \\
\hline
\end{tabular}

The surface energies range from 49 to $54 \mathrm{meV} / \AA^{2}$, and the difference between different magnetic phases is less than 5 $\mathrm{meV} / \AA^{2}$. To rationalize this small variation, we note that the surface energy increases mainly from the cost of $\mathrm{Ni}-\mathrm{O}$ bond cleavage when creating a new surface. Considering the exchange coupling between magnetic cations, cleavage of the $\mathrm{Ni}-\mathrm{O}$ bond might introduce an additional cost originating from the loss of the corresponding exchange interaction. Because the exchange interaction between $\mathrm{Ni}^{2+}$ is largely determined by $J_{2}$, the estimated cost of breaking the $J_{2}$ interaction when creating a new surface is $\sim 1.7 \mathrm{meV} / \AA^{2}$. Namely, the contribution from the long-range AFM phases to the surface energy is indeed small. Compared to the calculated overall surface energy, the contribution from magnetism $(\sim 3 \%)$ is negligible.

\subsubsection{Adsorption of CO and NO molecules}

$\mathrm{CO}$ and $\mathrm{NO}$ adsorption on these nonequivalent surfaces at a coverage of 0.25 monolayer with respect to surface $\mathrm{Ni}$ was
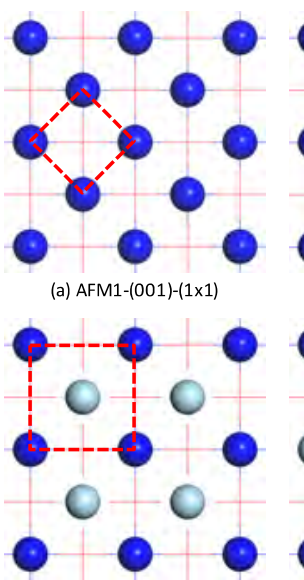

(d) AFM3-(001)- $(\sqrt{2} \times \sqrt{2})$

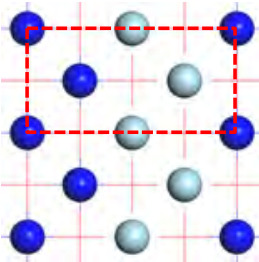

(g) AFM4-(100)-(2 $\sqrt{2} x \sqrt{2})$ (a) AFM1-(001)-(1×1)

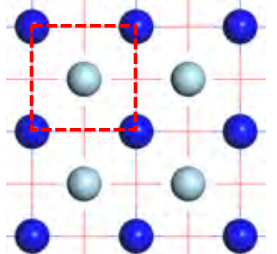

(b) AFM1-(100)-( $(\sqrt{2} \times \sqrt{2})$

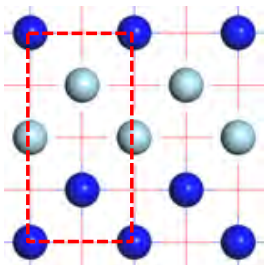

(e) AFM3-(100)- $-(\sqrt{2} \times 2 \sqrt{2})$

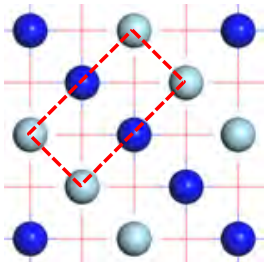

(h) AFM5-(001)-(1×2)

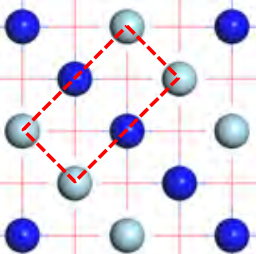

(c) AFM2-(001)-(1 $\times 2)$

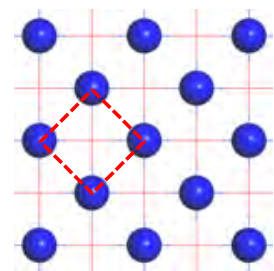

(f) AFM4-(001)-(1x1)

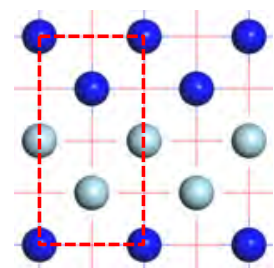

(i) AFM $-(100)-(\sqrt{2} \times 2 \sqrt{2})$
Fig. 3. Top view configuration of various nonequivalent $\mathrm{NiO}(001)$ surfaces taking into account of magnetism. Surface primitive cells are marked by frame of red dash line. 

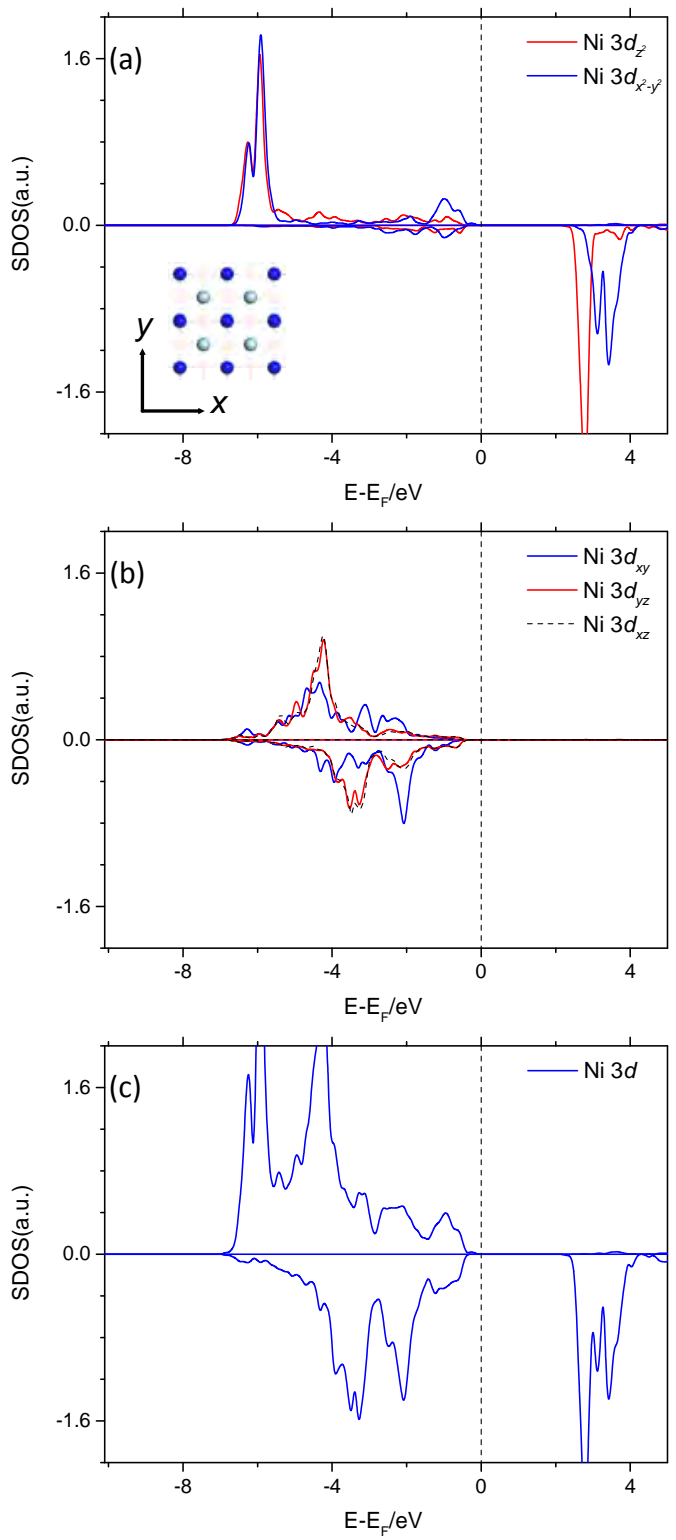

Fig. 4. Spin-resolved projected density of states (SDOS) for upward magnetic moment $\mathrm{Ni}(\uparrow)$ of clean NiO AFM2(001). (a) SDOS projected onto Ni $3 d_{z^{2}}, 3 d_{x^{2}-y^{2}}$; (b) SDOS projected onto Ni $3 d_{x y}, 3 d_{y z}, 3 d_{x z}$; (c) Total SDOS of Ni $3 d$. The reference coordinates for DOS projection is shown in inset of (a), where $x$-axis represents for [100] direction and $y$-axis for [010] direction.

studied. Various adsorption sites were considered, and the results for adsorption at the energetically most favorable sites are given in Table 3. For the nonequivalent surfaces considered, calculated $\mathrm{CO}$ adsorption energies varied from -0.33 to $-0.37 \mathrm{eV}$, while NO adsorption energies were more exothermic and ranged from -0.42 to $-0.46 \mathrm{eV}$. The small change of adsorption energies $(0.04 \mathrm{eV}$; less than $10 \%)$ reveals the weak influence of the long-range magnetic phases on both $\mathrm{CO}$ and NO adsorption. The calculated adsorption energies are in good agreement with those obtained from a previous GGA+U calculation on a (001) surface of $\mathrm{NiO}$ with AFM2 magnetic order and thermodesorption and infrared experiments $(-0.30$ to $-0.45 \mathrm{eV}$ for $\mathrm{CO}$ and -0.52 to $-0.57 \mathrm{eV}$ for NO) $[37,38,46-48]$.
Table 3

Magnetism and structure information of $\mathrm{CO}$ adsorption on $\mathrm{NiO}\{001\}$. Magnetic moment $\left(M_{\mathrm{Ni}}, M_{\mathrm{CO}}\right)$ is given in unit of $\mu_{\mathrm{B}}$. Adsorption energy of $\mathrm{CO} E_{\text {ads }}$ is given in eV. Bond length $\left(d_{\mathrm{Ni}-\mathrm{C}}\right)$ is given in $\AA$.

\begin{tabular}{lccccc}
\hline & $M_{\mathrm{Ni} \text { clean })}(\uparrow) / \mu_{\mathrm{B}}$ & $M_{\mathrm{Ni}}(\uparrow) / \mu_{\mathrm{B}}$ & $M_{\mathrm{Co}} / \mu_{\mathrm{B}}$ & $d_{\mathrm{Ni}-\mathrm{C}} / \AA$ & $E_{\text {ads }} / \mathrm{eV}$ \\
\hline AFM1(001) & 1.80 & 1.78 & 0.01 & 2.04 & -0.34 \\
AFM1(100) & 1.81 & 1.78 & 0.02 & 2.05 & -0.34 \\
AFM2(001) & 1.72 & 1.69 & 0.01 & 2.07 & -0.36 \\
AFM3(001) & 1.78 & 1.76 & 0.02 & 2.05 & -0.33 \\
AFM3(100) & 1.77 & 1.74 & 0.01 & 2.04 & -0.34 \\
AFM4(001) & 1.78 & 1.76 & 0.01 & 2.05 & -0.34 \\
AFM4(100) & 1.77 & 1.74 & 0.02 & 2.04 & -0.35 \\
AFM5(001) & 1.74 & 1.70 & 0.01 & 2.02 & -0.37 \\
AFM5(100) & 1.75 & 1.72 & 0.02 & 2.04 & -0.34 \\
FM(001) & 1.80 & 1.77 & 0.02 & 2.05 & -0.35 \\
\hline
\end{tabular}

In line with its weak binding strength, $\mathrm{CO}$ adsorption induces little change of the magnetism (less than $0.02 \mu \mathrm{B}$ ) of $\mathrm{CO}$ and coordinated Ni atom. As shown in Figure 5(a), CO adsorbed nearly perpendicularly at the top of a $\mathrm{Ni}$ atom. The optimized $\mathrm{Ni}-\mathrm{C}$ bond length varied from 2.02 to $2.07 \AA$, where a shorter bond length indicates stronger binding. Meanwhile, the $\mathrm{C}-\mathrm{O}$ bond length of $1.14 \AA$ was the same as that of gas-phase CO. Small tilting of the angle between the $\mathrm{Ni}-\mathrm{C}$ and $\mathrm{C}-\mathrm{O}$ bonds could be energetically favorable; however, the variation of the corresponding potential energy surface was less than $10 \mathrm{meV}$ for tilt angles up to $30^{\circ}$ [37].

The bonding mechanism between $\mathrm{CO}$ and a coordinated $\mathrm{Ni}$ atom can be inferred from the corresponding SDOS plotted in Figure 5(b). The hybridization is mainly between the CO $5 \sigma$ orbital and $\mathrm{Ni} 3 d_{z^{2}}$ band in the bottom of the valence band (donation). In addition, there is weak hybridization between $\mathrm{CO}$ $2 \pi^{*}$ and Ni $3 d_{x^{2}-y^{2}}$ in the conduction band (back donation). The fact that both hybridizations appear far from the Fermi level rationalizes well the weak binding strength of adsorbed CO.
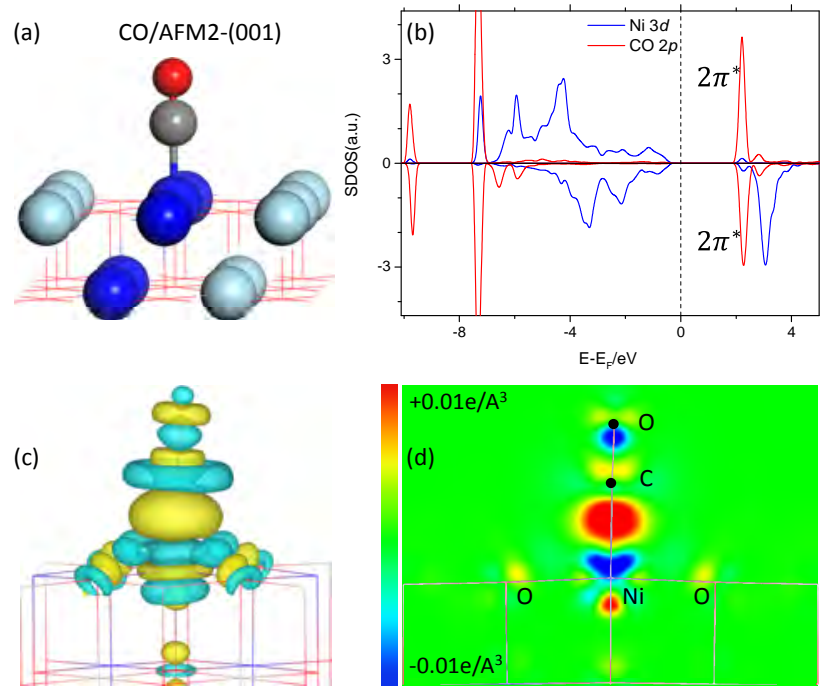

Fig. 5. CO adsorption on NiO AFM2(001). (a) Adsorption configuration; (b) SDOS of Ni $3 d$ and CO $2 p$ orbitals; (c) Isosurface view; (d) Section contour view of difference of electron density for $\mathrm{CO}$ adsorption. For isosurface view, yellow/green color means electron accumulation/ depletion respectively. 
Direct visualization of the bonding between $\mathrm{CO}$ and Ni can be better seen from the difference of electron density (Figure 5(c) and (d)). Pronounced charge accumulation between CO and coordinated $\mathrm{Ni}$ is observed, which indicates the dominating role of the donation interaction in $\mathrm{CO}$ adsorption on a $\mathrm{NiO}(001)$ surface.

Compared with the case for CO adsorption, NO binds more strongly to $\mathrm{Ni}$ with a tilted configuration (Figure 6(a)), in agreement with previous studies of $\mathrm{NO}$ adsorption on $\mathrm{NiO}(100)$ [38] and transition metal surfaces [49,50]. For instance, on AFM2-(001), the tilt angle is $10.7^{\circ}$ for the $\mathrm{Ni}-\mathrm{N}$ bond and $49.5^{\circ}$ for the $\mathrm{N}-\mathrm{O}$ bond. Depending on the magnetic phase (Table 4), the optimized $\mathrm{Ni}-\mathrm{N}$ bond length varies in the range of 1.98-2.05 $\AA$, and the configuration with a shorter $\mathrm{Ni}-\mathrm{N}$ bond length is consistent with stronger binding. The $\mathrm{N}-\mathrm{O}$ bond length (1.17-1.18 $\AA$ ) is nearly the same as that of the gas phase (1.17 $\AA$ ). After NO adsorption, the magnetic moments of NO and coordinated Ni decrease by about 0.10 and $0.20 \mu_{\mathrm{B}}$, respectively. Interestingly, the magnetic moment of adsorbed NO is always antiparallel with coordinated $\mathrm{Ni}$ irrespective of the surfaces magnetic phase; this will be discussed further later.

Upon NO adsorption, the hybridization between the NO $5 \sigma$ orbital and Ni $3 d_{z^{2}}$ band in the bottom of the valence band decreases slightly (Figure 6(b)). Compared to the CO $2 \pi^{*}$ orbital, which is completely unoccupied, the NO $2 \pi^{*}$ orbital in the top of the valence band is partially occupied. For $\mathrm{Ni}(\uparrow)$, it is mainly the Ni $3 d_{x z, y z}$ spin-down component populated in the top/upper part of the valence band. To maximize the hybridization between NO $2 \pi^{*}$ and Ni $3 d_{x z, y z}$ in the top/upper part of the valence band, the occupied NO $2 \pi^{*}$ must populate the spin-down component. In other words, the favorable configuration of magnetic moment between NO and coordinated Ni is antiparallel, namely, NO( $\downarrow$ ) and coordinated $\mathrm{Ni}(\uparrow)$, which is also found for NO adsorption on $\mathrm{NiO}(011)$.
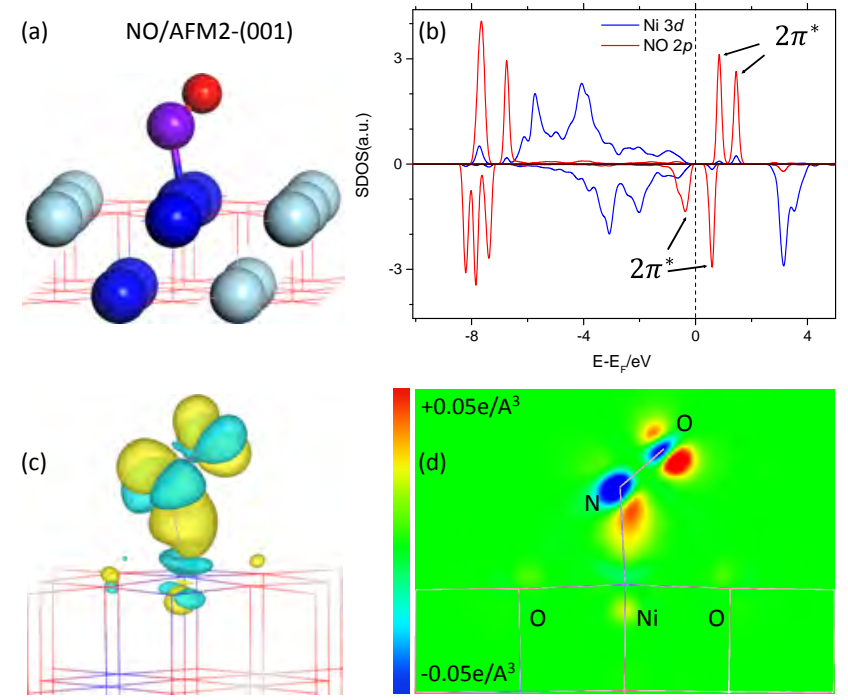

Fig. 6. NO adsorption on AFM2(001). (a) Adsorption configuration; (b) SDOS of Ni $3 d$ and NO $2 p$ orbitals; (c) Isosurface view; (d) Section contour view of difference of electron density for NO adsorption. For isosurface view, yellow/green color means electron accumulation/ depletion respectively.
Table 4

Magnetism and structure information of NO adsorption on NiO $\{001\}$ surfaces. Magnetic moment $\left(M_{\mathrm{Ni}}, M_{\mathrm{NO}}\right)$ is given in unit of $\mu_{\mathrm{B}}$. Adsorption energy of NO $\left(E_{\text {ads }}\right)$ is given in eV. Bond length $\left(d_{\mathrm{Ni-N}}\right)$ is given in $\AA$.

\begin{tabular}{lccccc}
\hline & $M_{\mathrm{Ni} \text { (clean) }}(\uparrow) / \mu_{\mathrm{B}}$ & $M_{\mathrm{Ni}}(\uparrow) / \mu_{\mathrm{B}}$ & $M_{\mathrm{NO}}(\downarrow) / \mu_{\mathrm{B}}$ & $d_{\mathrm{Ni}-\mathrm{N}} / \AA$ & $E_{\text {ads }} / \mathrm{eV}$ \\
\hline AFM1(001) & 1.80 & 1.63 & -0.61 & 2.00 & -0.45 \\
AFM1(100) & 1.81 & 1.63 & -0.61 & 2.00 & -0.46 \\
AFM2(001) & 1.72 & 1.56 & -0.58 & 2.05 & -0.42 \\
AFM3(001) & 1.78 & 1.62 & -0.63 & 2.01 & -0.44 \\
AFM3(100) & 1.77 & 1.59 & -0.60 & 1.98 & -0.45 \\
AFM4(001) & 1.78 & 1.62 & -0.62 & 2.00 & -0.44 \\
AFM4(100) & 1.77 & 1.59 & -0.57 & 1.98 & -0.45 \\
AFM5(001) & 1.74 & 1.56 & -0.61 & 1.98 & -0.45 \\
AFM5(100) & 1.75 & 1.58 & -0.58 & 1.99 & -0.44 \\
FM(001) & 1.80 & 1.63 & -0.56 & 1.99 & -0.45 \\
\hline
\end{tabular}

Regarding the decrease of the magnetic moment of adsorbed NO, we note that the peak intensity of NO $2 \pi^{*}$ at the top of the valence band is smaller than those of the three other peaks of NO $2 \pi^{*}$ in the conduction band. This indicates the electron depletion in the corresponding states (spin-down component), and accordingly, the NO magnetic moment decreases. Similarly, the decrease of the magnetic moment of coordinated $\mathrm{Ni}$ can be rationalized by the depletion of $\mathrm{Ni} 3 d_{z^{2}}$ states (lower peak intensity) at the bottom of the valence band (spin-up component).

Compared to $\mathrm{CO}$ adsorption, the extra hybridization between NO $2 \pi^{*}$ and Ni $3 d_{x z, y z}$ in the valence band strengthens the binding between $\mathrm{NO}$ and the coordinated $\mathrm{Ni}$ atom. The direct participation of the NO $2 \pi^{*}$ orbital can be clearly seen from the difference of electron density plotted in Figure 6(c) and (d). Moreover, the magnitude of the difference of electron density induced by NO adsorption is about five times larger than that of CO (Figure 6(d) versus Figure 5(d)). The larger extent of electron redistribution induced by NO than by $\mathrm{CO}$ corroborates well with its stronger binding strength. For both $\mathrm{CO}$ adsorption (Figure 6(c) and (d)) and NO adsorption (Figure 5(c) and (d)), the adsorption-induced charge redistribution is limited to the singly coordinated $\mathrm{Ni}$ atom, and electrons of the $\mathrm{NN} \mathrm{Ni}$ are hardly affected. In other words, the long-range magnetic phase has little influence on NO and CO adsorption on NiO(001).

\section{3. $\mathrm{NiO}(011)$}

\subsubsection{Surface properties}

Without considering the magnetic phases, the $\{011\}$ plane family consists of twelve equivalent planes. When taking into account the magnetism, the symmetry and degeneracy are broken. As listed in Table 5 and plotted schematically in Figure 7, for AFM1, AMF2, AFM3, and AFM4, there are two nonequivalent surfaces, and for AFM5, there are three inequivalent surfaces. This gives a total of eleven nonequivalent surfaces. For nonequivalent AFM1-(011), AFM2-(01') , AFM3-(110), and

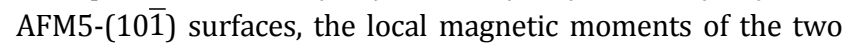
adjacent surface $\mathrm{Ni}$ atoms are exclusively antiparallel $(\uparrow \downarrow)$. Conversely, for nonequivalent AFM1-(110), AFM2-(011), AFM4-(110), and AFM5-(101) surfaces, the local magnetic 
Table 5

Nonequivalent surface of rock salt $\mathrm{NiO}\{011\}$ plane family taking into account of magnetism. The surface in each column remains equivalent from each other. Corresponding surface energy $\gamma\left(\mathrm{meV} / \AA^{2}\right)$ is given, and as reference for $\mathrm{FM} \mathrm{NiO}(011), \gamma=165 \mathrm{meV} / \AA^{2}$.

\begin{tabular}{|c|c|c|c|c|c|}
\hline & AFM1 & AFM2 & AFM3 & AFM4 & AFM5 \\
\hline \multirow[t]{9}{*}{$\gamma$} & 162163 & $172 \quad 172$ & $166 \quad 165$ & $167 \quad 167$ & $\begin{array}{lll}169 & 170 & 170\end{array}$ \\
\hline & $(011)(110)$ & $(011)(01 \overline{1})$ & $(011)(110)$ & (011) (110) & $(011)(101)(10 \overline{1})$ \\
\hline & $(0 \overline{1} \overline{1})(\overline{1} \overline{1} 0)$ & $(0 \overline{1} \overline{1})(0 \overline{1} 1)$ & $(0 \overline{1} \overline{1})(\overline{1} \overline{1} 0)$ & $(0 \overline{11})(\overline{1} \overline{1} 0)$ & $(0 \overline{1} \overline{1})(\overline{1} 0 \overline{1})(\overline{1} 01)$ \\
\hline & $(0 \overline{1} 1)(\overline{1} 10)$ & $(101)(10 \overline{1})$ & $(01 \overline{1})(1 \overline{1} 0)$ & $(01 \overline{1})(1 \overline{1} 0)$ & $(01 \overline{1})$ \\
\hline & $(01 \overline{1})(1 \overline{1} 0)$ & $(\overline{1} 0 \overline{1})(\overline{1} 01)$ & $(0 \overline{1} 1)(\overline{1} 10)$ & $(0 \overline{1} 1)(\overline{1} 10$ & $(0 \overline{1} 1)$ \\
\hline & $(101)$ & $(110)(1 \overline{1} 0)$ & (101) & (101) & (110) \\
\hline & $(\overline{1} 0 \overline{1})$ & $(\overline{1} 10)(\overline{1} 10)$ & $(\overline{1} 0 \overline{1})$ & $(\overline{1} 0 \overline{1})$ & $(\overline{1} \overline{1} 0)$ \\
\hline & $(10 \overline{1})$ & & $(10 \overline{1})$ & $(10 \overline{1})$ & $(1 \overline{1} 0)$ \\
\hline & $(\overline{1} 01)$ & & $(\overline{1} 01)$ & $(\overline{1} 01)$ & $(\overline{1} 10)$ \\
\hline
\end{tabular}

moments of two adjacent surface $\mathrm{Ni}$ atoms are exclusively parallel ( $\uparrow)$. For the nonequivalent AFM3-(011), AFM4-(011), and AFM5-(011) surfaces, both $(\uparrow \downarrow)$ and $(\uparrow \uparrow)$ pairs (noted as X1 and

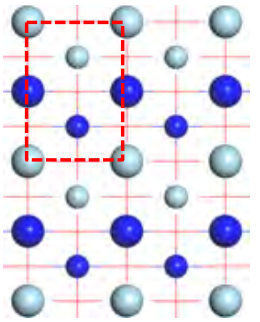

(a) AFM1-(011)-(1 $\times 2)$

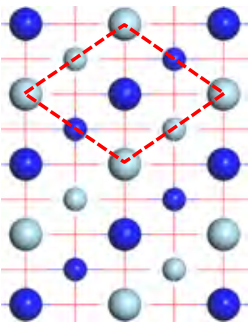

(d) AFM2-(011) $-(\sqrt{2} \times \sqrt{2})$

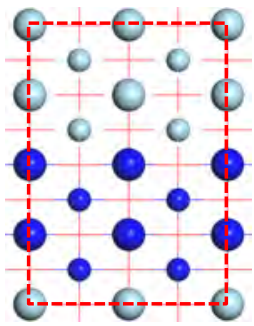

(g) AFM4-(011)-(2x4)

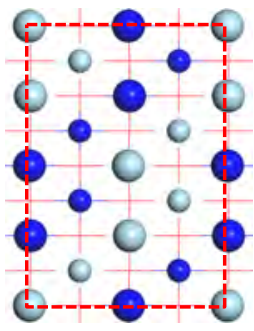

(j) AFM5-(011)-(2×4)

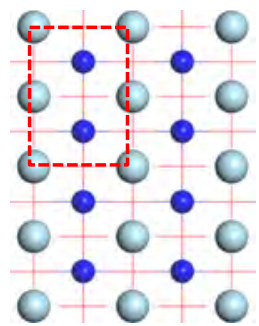

(b) AFM1-(110)-(1×2)

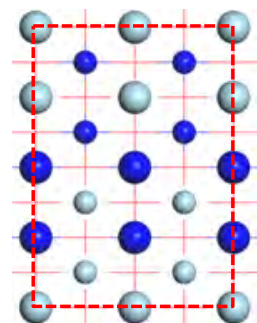

(e) AFM3-(011)-(2×4)

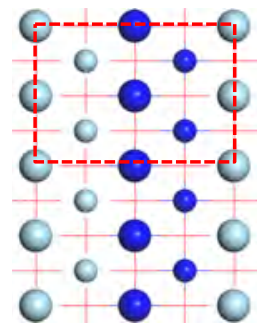

(h) AFM4-(110)-(2×2)

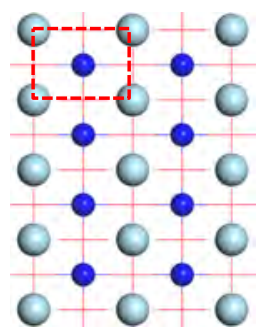

(k) AFM5-(101)-(1×1)

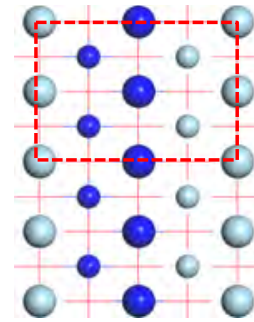

(c) AFM2-(011)-(2×2)

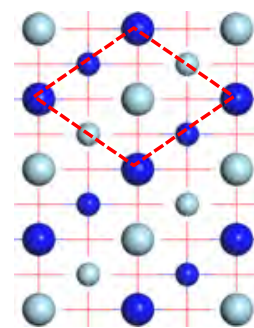

(f) AFM3-(110)- $(\sqrt{2} \times \sqrt{2})$

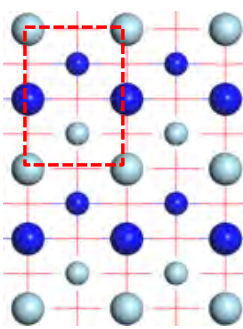

(i) AFM5-(101) $-(1 \times 2)$
Fig. 7. Top view configuration of nonequivalent $\mathrm{NiO}(110)$ surfaces taking into account of magnetism. Ni atoms at top and second layer are presented with larger and smaller ball, respectively.

\section{$\mathrm{X} 2$, respectively) coexist.}

The calculated energies of $\{011\}$ surfaces are summarized in Table 5. For the nonequivalent surfaces, the calculated surface energies vary from 162 to $172 \mathrm{meV} / \AA^{2}$. These energies are about three times larger than those of $\mathrm{NiO}\{001\}$, because more $\mathrm{Ni}-\mathrm{O}$ bonds (per unit area) are broken to create the new surface from the bulk material. In contrast, the surface energies of the nonequivalent surfaces belonging to the same AFM phase differ only by $1 \mathrm{meV} / \AA^{2}$. This means that the variation of the surface energies by $10 \mathrm{meV} / \AA^{2}$ mainly originates from the different long-range magnetic phases. Although the absolute variation of surface energies is about twice that of $\mathrm{NiO}\{001\}$ surfaces, the contribution to the overall surface energies remains small $(\sim 6 \%)$. This shows again the weak effect of the magnetic phases on surface energies.

Figure 8 plots the SDOS of a surface $\mathrm{Ni}$ atom ( $\uparrow$ ) of AFM2-(011). The $3 d_{x^{2}-y^{2}}$ and $3 d_{y z}$ states are populated mainly in the bottom of the valence band (spin up) and the lower part of
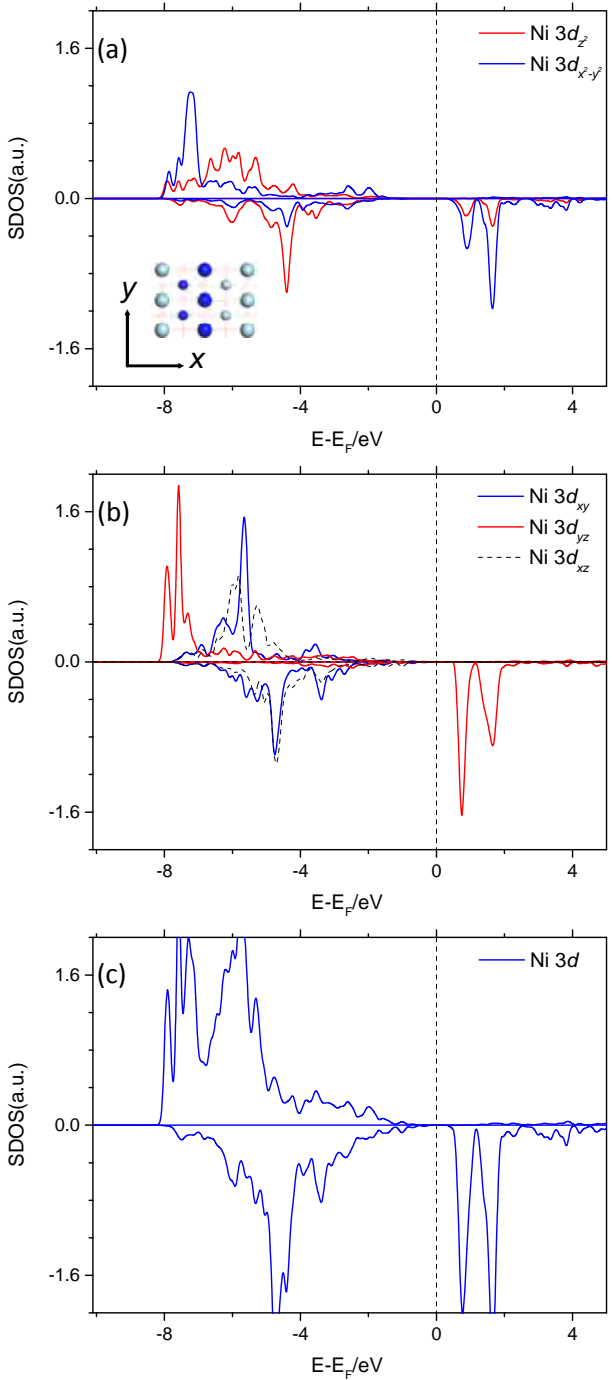

Fig. 8. Spin-resolved projected density of states (SDOS) for Ni of clean AFM2 NiO(011). (a) Total SDOS of Ni 3d; (b) SDOS projected onto Ni $3 d_{z^{2}}, 3 d_{x^{2}-y^{2}}$; (c) SDOS projected onto Ni $3 d_{x y}, 3 d_{y z}, 3 d_{x z}$. The reference coordinates for SDOS projection is shown in inset of $(\mathrm{a})$, where $x$-axis represents for [100] direction and $y$-axis for [011] direction. 
the conduction band (spin down), while $3 d_{z^{2}}, 3 d_{x z}$, and $3 d_{x y}$ are populated in the valence band. The upper part of the valence band originates largely from $\mathrm{Ni} 3 d_{x y, x z}$ (spin down). Another prominent feature is the gap between the VBM and CBM of the $\mathrm{Ni} 3 d$ band of $1.40 \mathrm{eV}$, which is much smaller than that of AFM2-(001) (2.81 eV) and AFM2 bulk (3.23 eV). The smaller $3 d$ band gap of the surface Ni might facilitate its hybridization with adsorbed molecules, which will be discussed below.

\subsubsection{CO adsorption}

$\mathrm{CO}$ adsorption on these nonequivalent surfaces was studied, and the results at the most favorable sites are listed in Table 6 . $\mathrm{CO}$ prefers to adsorb exclusively via the end of the $\mathrm{C}$ atom at the bridge site of two adjacent Ni atoms, labeled as A and B (Figure 9(a) and (c)). Irrespective of the nonequivalent surfaces and different bridge sites ( $\uparrow$ and $\uparrow \downarrow$ ) considered, CO has similar adsorption energies at the $(\uparrow \downarrow)$ bridge sites (Figure 9(e)); the calculated adsorption energies vary from -0.73 to $-0.75 \mathrm{eV}$. Conversely, for CO adsorption at the $(\uparrow \uparrow)$ bridge sites (Figure 9(b)), the calculated adsorption energies are smaller ( -0.71 to $-0.72 \mathrm{eV}$ ). Thus, the local magnetic moment and its relative direction of two coordinated $\mathrm{Ni}$ atoms are responsible for the variation of the calculated adsorption energies rather than the long-range magnetic phases. The calculated binding strengths of $\mathrm{CO}$ on $\mathrm{NiO}\{011\}$ are about twice that of $\mathrm{CO}$ on $\mathrm{NiO}\{001\}$, which possibly arises from the greater number of $\mathrm{Ni}-\mathrm{C}$ bonds involved and the lower coordination number of surface Ni atoms.

Important geometrical parameters and the bond lengths between $\mathrm{C}$ and two coordinated $\mathrm{Ni}$ atoms are given in Table 6 . The optimized $\mathrm{C}-\mathrm{Ni}$ bond lengths are in the range of 2.13-2.23 $\AA$, and longer than those of $\mathrm{CO}$ adsorbed on $\mathrm{NiO}(001)$ (2.02-2.07 $\AA$ ). Irrespective of the magnetic phases considered, the $\mathrm{C}-\mathrm{O}$ bond lengths stayed at a constant value of $1.15 \AA$,
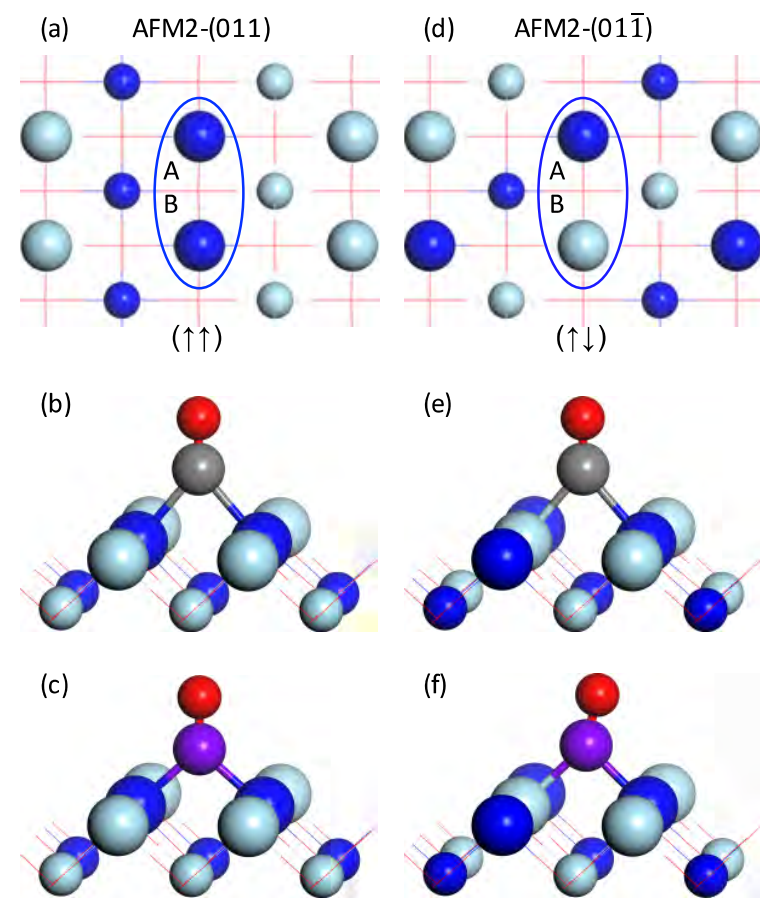

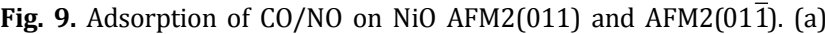
AFM2(011) surface with bridge sites of $\mathrm{Ni}(\mathrm{A}, \uparrow)$ and $\mathrm{Ni}(\mathrm{B}, \uparrow)$; (b) $\mathrm{CO}$ and (c) NO adsorbed configuration on AFM2(011); (d) AFM2(01) 1 ) surface with bridge sites of $\mathrm{Ni}(\mathrm{A}, \uparrow$ ) and $\mathrm{Ni}(\mathrm{B}, \downarrow)$; (e) CO and (f) NO adsorbed configuration on $\mathrm{AFM} 2(01 \overline{1})$.

which is $0.01 \AA$ A longer than that of gas-phase CO. CO adsorption has little influence on the surface magnetism: the magnetic moment for $\mathrm{CO}$ and coordinated $\mathrm{Ni}$ atoms decreased by only about 0.02 and $0.05 \mu_{\mathrm{B}}$, respectively.

SDOS for CO adsorption at the ( $\uparrow$ )-bridge sites of AFM2 NiO(011) are plotted in Figure 10(a). The magnetic moments of

Table 6

Magnetism and structure information of CO adsorption at the ( $\uparrow)$-bridge and ( $\downarrow \downarrow)$-bridge sites of NiO \{011\} surfaces. Ni(A) always labels the Ni with total magnetic moment spin up. Magnetic moment $\left(M_{\mathrm{Ni}}, M_{\mathrm{CO}}\right)$ is given in unit of $\mu_{\mathrm{B}}$. Bond length $\left(d_{\mathrm{Ni}-\mathrm{C}}\right)$ is given in $\AA$. Adsorption energy of CO ( $\left.E_{\mathrm{ads}}\right)$ is given in $\mathrm{eV}$.

\begin{tabular}{|c|c|c|c|c|c|c|c|}
\hline & $M_{\text {Ni(clean })} / \mu_{\mathrm{B}}$ & $M_{\mathrm{Ni}(\mathrm{A})} / \mu_{\mathrm{B}}$ & $M_{\mathrm{Ni}(\mathrm{B})} / \mu_{\mathrm{B}}$ & $M_{\mathrm{C} 0} / \mu_{\mathrm{B}}$ & $d_{\mathrm{Ni}(\mathrm{A})-\mathrm{C}} / \AA ̊$ & $d_{\mathrm{Ni}(\mathrm{B})-\mathrm{C}} / \AA$ & $E_{\text {ads }} / \mathrm{eV}$ \\
\hline$(\uparrow \downarrow)$-bridge & & $(\uparrow)$ & $(\downarrow)$ & & & & \\
\hline AFM1(011) & 1.77 & 1.72 & -1.72 & 0.01 & 2.13 & 2.15 & -0.73 \\
\hline AFM2 $(01 \overline{1})$ & 1.70 & 1.66 & -1.66 & 0.00 & 2.18 & 2.18 & -0.74 \\
\hline AFM3(011)X1 & 1.75 & 1.73 & -1.73 & 0.04 & 2.19 & 2.16 & -0.75 \\
\hline AFM3(110) & 1.74 & 1.68 & -1.68 & 0.00 & 2.13 & 2.13 & -0.74 \\
\hline AFM4(011)X1 & 1.75 & 1.72 & -1.72 & -0.05 & 2.16 & 2.19 & -0.72 \\
\hline AFM5(011)X1 & 1.72 & 1.67 & -1.66 & 0.00 & 2.14 & 2.12 & -0.74 \\
\hline $\operatorname{AFM} 5(10 \overline{1})$ & 1.72 & 1.67 & -1.66 & -0.01 & 2.14 & 2.12 & -0.74 \\
\hline$(\uparrow \uparrow)$-bridge & & $(\uparrow)$ & $(\uparrow)$ & & & & \\
\hline AFM1(110) & 1.78 & 1.74 & 1.74 & 0.02 & 2.17 & 2.17 & -0.71 \\
\hline AFM2(011) & 1.70 & 1.68 & 1.68 & 0.03 & 2.17 & 2.19 & -0.71 \\
\hline AFM3(011)X2 & 1.75 & 1.72 & 1.72 & 0.05 & 2.18 & 2.19 & -0.71 \\
\hline AFM4(011)X2 & 1.75 & 1.71 & 1.73 & 0.05 & 2.15 & 2.23 & -0.71 \\
\hline AFM4(110) & 1.74 & 1.69 & 1.69 & 0.00 & 2.15 & 2.14 & -0.72 \\
\hline AFM5(011)X2 & 1.72 & 1.69 & 1.69 & 0.03 & 2.16 & 2.19 & -0.71 \\
\hline AFM5(101) & 1.73 & 1.70 & 1.70 & 0.06 & 2.18 & 2.17 & -0.71 \\
\hline $\mathrm{FM}(011)$ & 1.78 & 1.75 & 1.75 & 0.06 & 2.17 & 2.18 & -0.71 \\
\hline
\end{tabular}



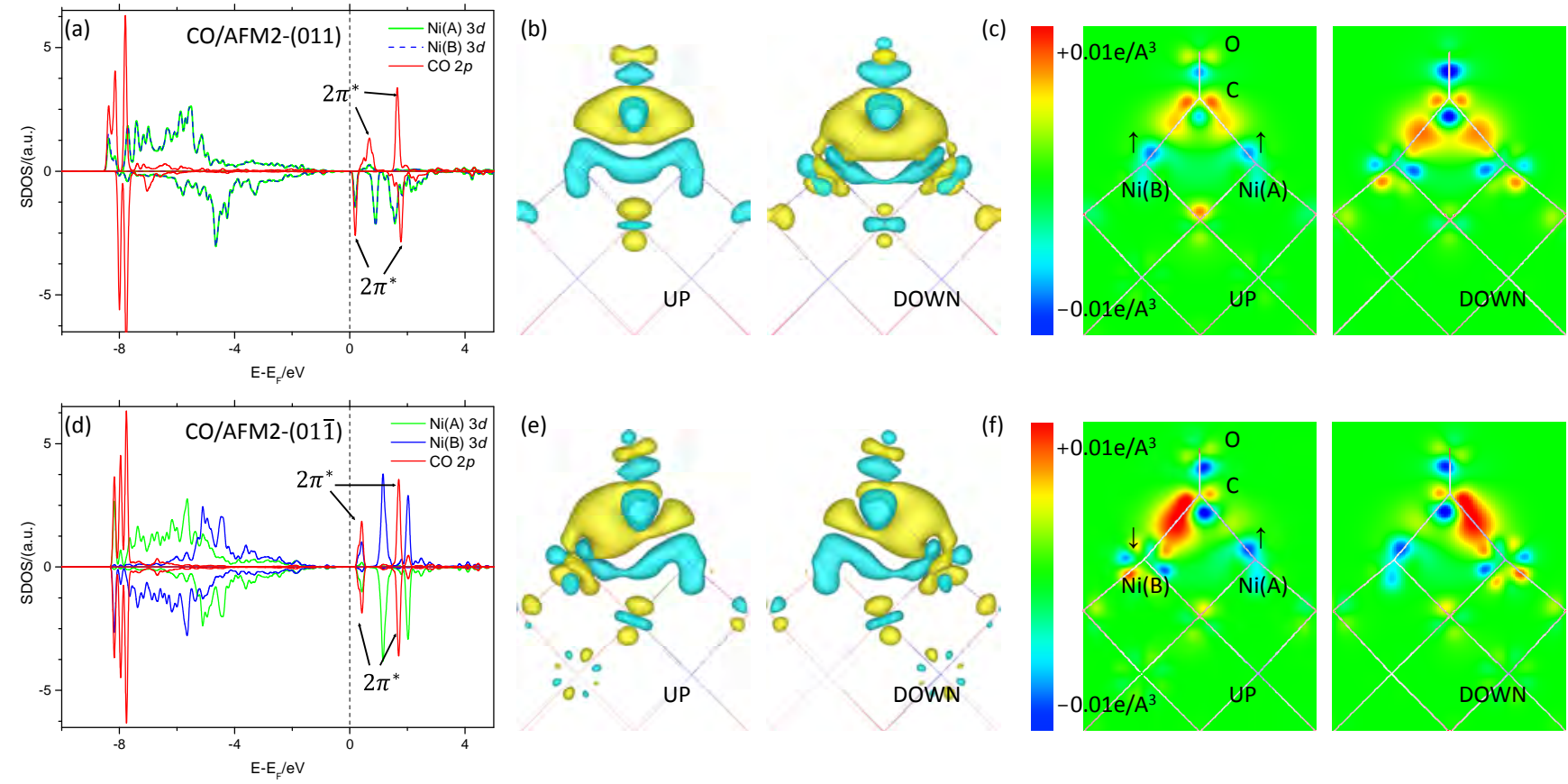

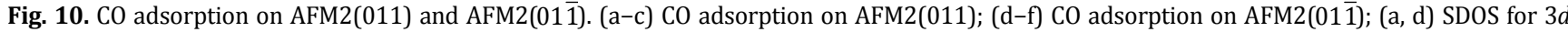
orbitals of $\mathrm{Ni}(\mathrm{A})$ and $\mathrm{Ni}(\mathrm{B})$ labeled in Figure 9 and $2 p$ orbitals of $\mathrm{CO}$; (b, e) Isosurface view and (c, f) section contour view of spin-resolved difference of electron density for $\mathrm{CO}$ adsorption with spin-up component labeled UP and spin-down component labeled DOWN, respectively.

both $\mathrm{Ni}(\mathrm{A})$ and $\mathrm{Ni}(\mathrm{B})$ point upwards, which are denoted as $\mathrm{Ni}(\mathrm{A}, \uparrow)$ and $\mathrm{Ni}(\mathrm{B}, \uparrow)$, respectively. Figure 10 (a) reveals that the spin-up components of $\mathrm{Ni}(\mathrm{A}, \uparrow)$ and $\mathrm{Ni}(\mathrm{B}, \uparrow)$ are nearly completely occupied. The hybridization occurs mainly via $\mathrm{Ni}(\mathrm{A}$, $\uparrow) / \mathrm{Ni}(\mathrm{B}, \uparrow)$ back-donation towards CO. In contrast, the spin-down components of $\mathrm{Ni}(\mathrm{A}, \uparrow)$ and $\mathrm{Ni}(\mathrm{B}, \uparrow)$ are partially occupied, and hybridization occurs via $\mathrm{CO}$ donation to $\mathrm{Ni}(\mathrm{A}$, $\uparrow) / \mathrm{Ni}(\mathrm{B}, \uparrow)$. Back donation in the spin-up component but donation in the spin down can be easily visualized in the spin-resolved difference of electron density results plotted in Figure 10(b) and (c). For the spin-up case, there is pronounced charge depletion from both $\mathrm{Ni}(\mathrm{A}, \uparrow)$ and $\mathrm{Ni}(\mathrm{B}, \uparrow)$ and accumulation in CO $2 \pi^{*}$ (back donation). For the spin-down component, there is charge depletion caused by CO $5 \sigma$ donation and accumulation mainly between $\mathrm{CO}$ and $\mathrm{Ni}(\mathrm{A}, \uparrow) / \mathrm{Ni}(\mathrm{B}, \uparrow)$.

SDOS for CO adsorption at the $(\uparrow \downarrow)$ bridge sites of AFM2(01 $\overline{1})$ are plotted in Figure 10(d), where the magnetic moments of $\mathrm{Ni}(\mathrm{A})$ and $\mathrm{Ni}(\mathrm{B})$ respectively point upwards ( $\uparrow$ ) and downwards $(\downarrow)$, and are denoted as $\mathrm{Ni}(\mathrm{A}, \uparrow)$ and $\mathrm{Ni}(\mathrm{B}, \downarrow)$, respectively. For the spin-up component, $\mathrm{Ni}(\mathrm{A}, \uparrow)$ is nearly fully occupied and $\mathrm{Ni}(\mathrm{B}, \downarrow)$ is partially occupied. Accordingly, the hybridization takes place via $\mathrm{Ni}(\mathrm{A}, \uparrow)$ back donation toward $\mathrm{CO}$, but CO donation toward $\mathrm{Ni}(\mathrm{B}, \downarrow)$. This can be observed in the spin-resolved difference of electron density of the system (Figure 10(e) and (f)). There is modest charge depletion at Ni(A, $\uparrow$ ) for back donation and pronounced charge accumulation between $\mathrm{CO}$ and $\mathrm{Ni}(\mathrm{B}, \downarrow)$ for $\mathrm{CO}$ donation. The relative larger extent of charge accumulation between $\mathrm{CO}$ and $\mathrm{Ni}(\mathrm{B}, \downarrow)$ than that of charge depletion at $\mathrm{Ni}(\mathrm{A}, \uparrow)$ indicates that donation rather than back donation plays a dominant role in the overall hybridization between $\mathrm{CO}$ and $\mathrm{Ni}$. For the spin-down component
(Figure $10(d)$ ), $\mathrm{Ni}(\mathrm{B}, \downarrow)$ is nearly fully occupied and $\mathrm{Ni}(\mathrm{A}, \downarrow)$ is partially occupied. Accordingly, the hybridization takes place via $\mathrm{Ni}(\mathrm{B}, \downarrow)$ back donation toward $\mathrm{CO}$ and $\mathrm{CO}$ donation toward $\mathrm{Ni}(\mathrm{A}, \uparrow)$. The distinct hybridization and charge redistribution for $\mathrm{CO}$ at the $(\uparrow \downarrow)$ bridge sites from that of the $(\uparrow \uparrow)$ bridge sites is in contrast to their similar adsorption energies (which differ by less than $0.03 \mathrm{eV}$ ).

\subsubsection{NO adsorption}

NO adsorption also occurs preferentially at the bridge site of two adjacent $\mathrm{Ni}$ atoms via the end of the $\mathrm{N}$ atom (Figure 9 (c) and (f)). For all nonequivalent surfaces considered, the calculated adsorption energies for NO at the $(\uparrow \downarrow)$ bridge sites are in the range of -0.99 to $-1.05 \mathrm{eV}$ and in the range of -1.21 to $-1.30 \mathrm{eV}$ at the $(\uparrow \uparrow)$ bridge sites. Different from CO, the binding strengths at the $(\uparrow \uparrow)$ bridge sites are about $0.3 \mathrm{eV}$ stronger than those at the $(\uparrow \downarrow)$ bridge sites. Moreover, the NO binding strength on $\mathrm{NiO}(011)$ is about three times stronger than that of NiO(001). For adsorption on $(\uparrow \uparrow)$ or $(\uparrow \downarrow)$ bridge sites, the difference of adsorption energy with variation of bulk magnetic order and surface index is less than $0.10 \mathrm{eV}$. In contrast, the variation of NO adsorption energy on all studied $\mathrm{NiO}(001)$ surfaces did not exceed $0.04 \mathrm{eV}$. This indicates that the larger variation of binding strength at all $(\uparrow \uparrow)$ bridge sites (or $(\uparrow \downarrow)$ bridge sites) of $\mathrm{NiO}(011)$ than that of $\mathrm{NiO}(001)$ may be simply caused by the higher surface activity of $\mathrm{NiO}(011)$. However, the difference of binding strength between adsorption at $(\uparrow \uparrow)$ bridge sites and that at $(\uparrow \downarrow)$ bridge sites of $\mathrm{NiO}(011)$ cannot be attributed to this reason. Again, the importance of the local magnetic order rather than the long-range magnetic phase is found here. 
Important geometrical parameters for NO adsorption on $\mathrm{NiO}(011)$ are given in Table 7. Irrespective of the different magnetic phases considered, the $\mathrm{N}-\mathrm{O}$ bond lengths stay constant at $1.19 \AA, 0.02 \AA$ longer than that of gas-phase NO. For NO adsorption at the $(\uparrow \uparrow)$ bridge sites, the two $\mathrm{N}-\mathrm{Ni}$ bond lengths are nearly same (1.96-1.97 ̊). The corresponding NO magnetic moment prefers to align antiparallel with the two coordinated $\mathrm{Ni}(\uparrow)$, namely, as $\mathrm{NO}(\downarrow)$, as also found for NO adsorption on $\mathrm{NiO}(001)$. The magnetic moments of NO and coordinated Ni atoms decreased by at most 0.25 and $0.13 \mu_{\mathrm{B}}$, respectively. For NO adsorption at the $(\uparrow \downarrow)$ bridge sites, the two N-Ni bond lengths were not the same. The shorter one varied from 1.93 to $1.97 \AA$ A. The magnetic moments of NO and Ni corresponding to the shorter $\mathrm{N}-\mathrm{Ni}$ bond pointed downwards $(\downarrow)$ and upwards ( $\uparrow$ ), decreasing by at most 0.43 and $0.20 \mu_{\mathrm{B}}$, respectively. The longer N-Ni bond length varied from 2.03 to $2.09 \AA$, and there was little change of the magnetic moment of coordinated $\mathrm{Ni}(\downarrow)$, which is understandable because of its relative longer $\mathrm{N}-\mathrm{Ni}$ bond length.

Calculated SDOS for NO at the $(\uparrow \uparrow)$ bridge sites of AFM2 $\mathrm{NiO}(011)$ is plotted in Figure 11(a), where the magnetic moments of both $\mathrm{Ni}(\mathrm{A})$ and $\mathrm{Ni}(\mathrm{B})$ point upwards and are denoted as $\operatorname{Ni}(\mathrm{A}, \uparrow)$ and $\mathrm{Ni}(\mathrm{B}, \uparrow)$, respectively. As noted above, the NO magnetic moment prefers to point downward $(\downarrow)$; namely, there are more electrons occupied in the NO spin-down component than in the spin-up component. More electrons in the NO spin-down component would facilitate the corresponding donation process. This was verified in the spin-resolved difference of electron density results plotted in Figure 11(b) and (c), where charge accumulated between NO and coordinated Ni(A, $\uparrow) / \mathrm{Ni}(\mathrm{B}, \uparrow)$. For the spin-up component, less electron occupation of the NO orbital would facilitate the corresponding back donation. This can be found in Figure 11(b) and (c), where charge depleted from coordinated $\mathrm{Ni}(\mathrm{A}, \uparrow) / \mathrm{Ni}(\mathrm{B}, \uparrow)$ and accu- mulated in the NO molecule.

Calculated SDOS for NO adsorbed at the $(\uparrow \downarrow)$ bridge sites of AFM2(01) is plotted in Figure 11(d), where the magnetic moments of $\mathrm{Ni}(\mathrm{A})$ and $\mathrm{Ni}(\mathrm{B})$ point upwards and downwards and are denoted as $\mathrm{Ni}(\mathrm{A}, \uparrow)$ and $\mathrm{Ni}(\mathrm{B}, \downarrow)$, respectively. The N-O bond length with $\mathrm{Ni}(\mathrm{A}, \uparrow)$ is shorter than that with $\mathrm{Ni}(\mathrm{B}, \downarrow)$, and the NO magnetic moment points downward accordingly. The hybridization between $\mathrm{NO}(\downarrow)$ and $\mathrm{Ni}(\mathrm{A}, \uparrow)$ with antiparallel magnetic configuration is essentially the same as that for NO adsorption on AFM2(011) because the electronic and magnetic configurations are the same. This can be seen further in the corresponding difference of electron density plots (Figure 11 (e) and (f)). Conversely, for $\mathrm{NO}(\downarrow)$ and $\mathrm{Ni}(\mathrm{B}, \downarrow)$ with same orientation of magnetic moments, the electronic hybridization between $\mathrm{NO}$ and $\mathrm{Ni}(\mathrm{B})$ is limited. Indeed, the difference of electron density (Figure 11(e) and (f)) between NO and Ni(B) becomes negligible, particularly in the spin-down component. This rationalizes well the weaker binding strength of NO adsorption at the $(\uparrow \downarrow)$ bridge sites than that of NO at the $(\uparrow \uparrow)$ bridge sites.

\section{Conclusions}

By constructing surface models of $\mathrm{NiO}$ with different magnetic phases, and using the paramagnetic molecule NO and nonparamagnetic molecule $\mathrm{CO}$ to probe the reactivity on (001) and (011) surfaces, we investigated the influence of magnetism on the surface chemistry of NiO. When the favorable adsorption sites involve only a single Ni cation, such as NO/CO adsorption at the top site of a $\mathrm{Ni}$ cation on the (001) surface, the long-range magnetic phases make little contribution to the overall adsorption behavior. The adsorption strength is primarily determined by chemical environment (such as surface orientation, coordination number, and adsorbed species). When the favorable

\section{Table 7}

Magnetism and structure information of NO adsorption at the ( $\uparrow$ )-bridge and ( $\downarrow \downarrow)$ bridge sites of $\mathrm{NiO}$ \{011\} surfaces. Ni(A) always labels the Ni with total magnetic moment spin up. Magnetic moment $\left(M_{\mathrm{Ni}}, M_{\mathrm{NO}}\right)$ is given in unit of $\mu_{\mathrm{B}}$. Bond length $\left(d_{\mathrm{Ni}-\mathrm{N}}\right)$ is given in $\AA$. Adsorption energy of NO $\left(E_{\mathrm{ads}}\right)$ is given in $\mathrm{eV}$.

\begin{tabular}{|c|c|c|c|c|c|c|c|}
\hline & $M_{\mathrm{Ni}(\text { clean })} / \mu_{\mathrm{B}}$ & $M_{\mathrm{Ni}(\mathrm{A})} / \mu_{\mathrm{B}}$ & $M_{\mathrm{Ni}(\mathrm{B})} / \mu_{\mathrm{B}}$ & $M_{\mathrm{NO}} / \mu_{\mathrm{B}}$ & $d_{\mathrm{Ni}(\mathrm{A})-\mathrm{N}} / \AA$ & $d_{\mathrm{Ni}(\mathrm{B}) \mathrm{N}} / \AA$ & $E_{\text {ads }} / \mathrm{eV}$ \\
\hline$(\uparrow \downarrow)$-bridge & & $(\uparrow)$ & $(\downarrow)$ & $(\downarrow)$ & & & \\
\hline$\overline{\mathrm{AFM} 1(011)}$ & 1.77 & 1.58 & -1.74 & -0.47 & 1.93 & 2.03 & -1.05 \\
\hline AFM2 $(01 \overline{1})$ & 1.70 & 1.56 & -1.71 & -0.39 & 1.96 & 2.07 & -1.01 \\
\hline AFM3(011)X1 & 1.75 & 1.54 & -1.79 & -0.64 & 1.95 & 2.08 & -1.01 \\
\hline AFM3(110) & 1.74 & 1.53 & -1.78 & -0.74 & 1.96 & 2.09 & -1.05 \\
\hline AFM4(011)X1 & 1.75 & 1.57 & -1.78 & -0.65 & 1.97 & 2.05 & -1.03 \\
\hline AFM5(011)X1 & 1.72 & 1.53 & -1.75 & -0.63 & 1.96 & 2.07 & -1.02 \\
\hline $\operatorname{AFM} 5(10 \overline{1})$ & 1.72 & 1.54 & -1.73 & -0.30 & 1.94 & 2.05 & -0.99 \\
\hline$(\uparrow \uparrow)$-bridge & & $(\uparrow)$ & $(\uparrow)$ & $(\downarrow)$ & & & \\
\hline AFM1(110) & 1.78 & 1.65 & 1.65 & -0.68 & 1.97 & 1.97 & -1.30 \\
\hline AFM2(011) & 1.70 & 1.57 & 1.57 & -0.61 & 1.97 & 1.97 & -1.21 \\
\hline AFM3(011)X2 & 1.75 & 1.61 & 1.63 & -0.49 & 1.96 & 1.97 & -1.26 \\
\hline AFM4(011)X2 & 1.75 & 1.61 & 1.74 & -0.47 & 1.96 & 1.97 & -1.26 \\
\hline AFM4(110) & 1.74 & 1.61 & 1.61 & -0.72 & 1.96 & 1.96 & -1.30 \\
\hline AFM5(011)X2 & 1.72 & 1.58 & 1.59 & -0.53 & 1.96 & 1.97 & -1.24 \\
\hline AFM5(101) & 1.73 & 1.61 & 1.61 & -0.53 & 1.97 & 1.97 & -1.23 \\
\hline $\mathrm{FM}(011)$ & 1.78 & 1.64 & 1.64 & -0.59 & 1.96 & 1.96 & -1.29 \\
\hline
\end{tabular}




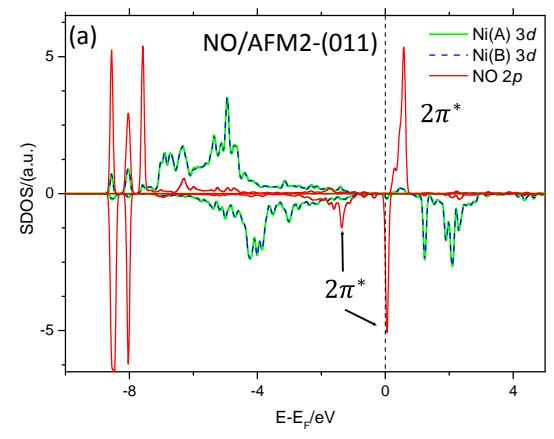

(b)

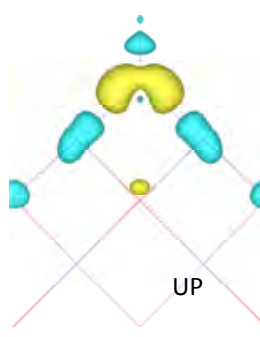

(e)

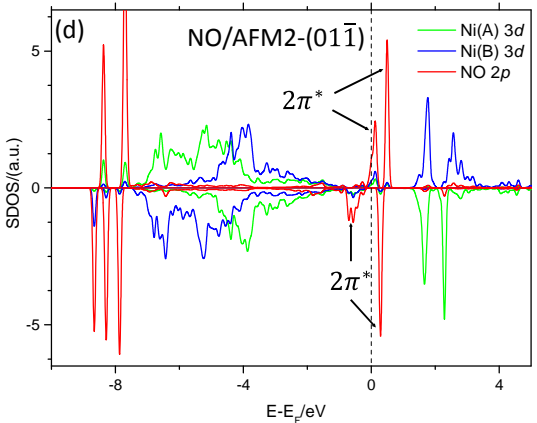

(c)
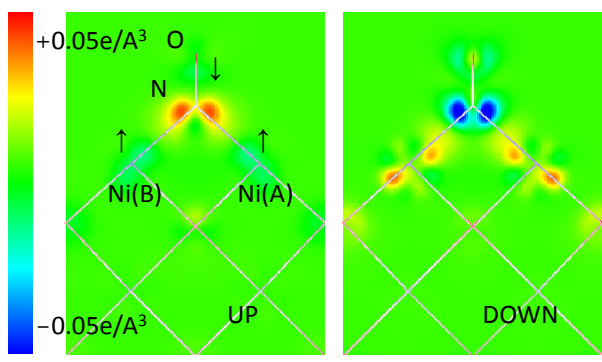

(f)
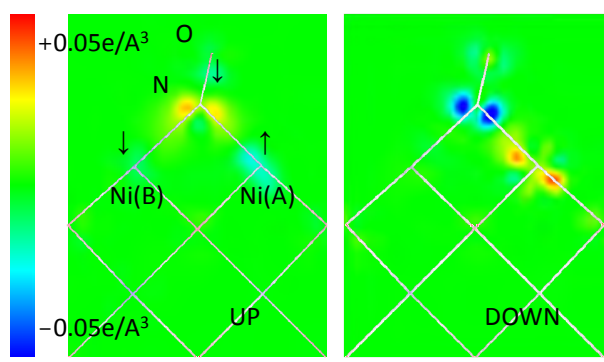

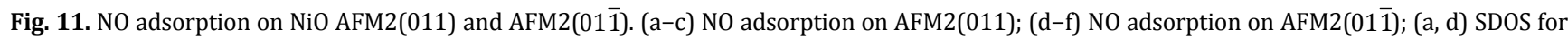
$3 d$ orbitals of $\mathrm{Ni}(\mathrm{A})$ and $\mathrm{Ni}(\mathrm{B})$ labeled in Figure 9 and $2 p$ orbitals of NO; (b, e) Isosurface view and (c, f) section contour view of spin-resolved charge flow diagram for NO adsorption with spin-up component labeled UP and spin-down component labeled DOWN, respectively.

adsorption site involves two adjacent $\mathrm{Ni}$ cations, such as $\mathrm{NO} / \mathrm{CO}$ adsorption at the bridge site of two Ni cations in $\mathrm{NiO}(011)$, the local magnetic order of $\mathrm{Ni}$ ions coordinated to the adsorbed molecule rather than the long-range magnetism makes a considerable contribution to the overall adsorption behavior. For nonparamagnetic molecule CO, the orbital hybridization for adsorption at the $(\uparrow \uparrow)$ bridge sites is very different from that at the $(\uparrow \downarrow)$ bridge sites, despite their incidental similar adsorption energies. For paramagnetic molecule NO, the hybridization at the $(\uparrow \uparrow)$ bridge sites is different from that at the $(\uparrow \downarrow)$ bridge sites, and the binding strength of the former is about $0.3 \mathrm{eV}$ stronger than that of the latter. The present work highlights the importance of the local magnetic order of TMO surfaces on molecule adsorption, particularly for paramagnetic molecules, at multi-fold sites.

\section{Acknowledgments}

We are grateful for the fruitful discussion with Prof. Hong Jiang.

\section{References}

[1] U. Diebold, S. C. Li, M. Schmid, Annu. Rev. Phys. Chem., 2010, 61, 129-148.

[2] J. F. Weaver, Chem. Rev., 2013, 113, 4164-4215.

[3] G. A. Somorjai, Y. M. Li, Proc. Natl. Acad. Sci. USA, 2011, 108, 917-924.

[4] S. Shaikhutdinov, H. J. Freund, Annu. Rev. Phys. Chem., 2012, 63, 619-633.

\section{Graphical Abstract}

Chin. J. Catal., 2017, 38: 1736-1748 doi: 10.1016/S1872-2067(17)62883-3

Influence of nickel(II) oxide surface magnetism on molecule adsorption: A first-principles study

Chuan-Qi Huang, Wei-Xue Li *

Dalian Institute of Chemical Physics, Chinese Academic of Sciences; University of Chinese Academy of Sciences;

University of Science and Technology of China

Calculations revealed that NO preferentially binds to Ni surfaces with its magnetic moment antiparallel to that of Ni. NO adsorbed at antiferromagnetic bridge sites binds to one $\mathrm{Ni}$ optimally and another in a frustrated manner.

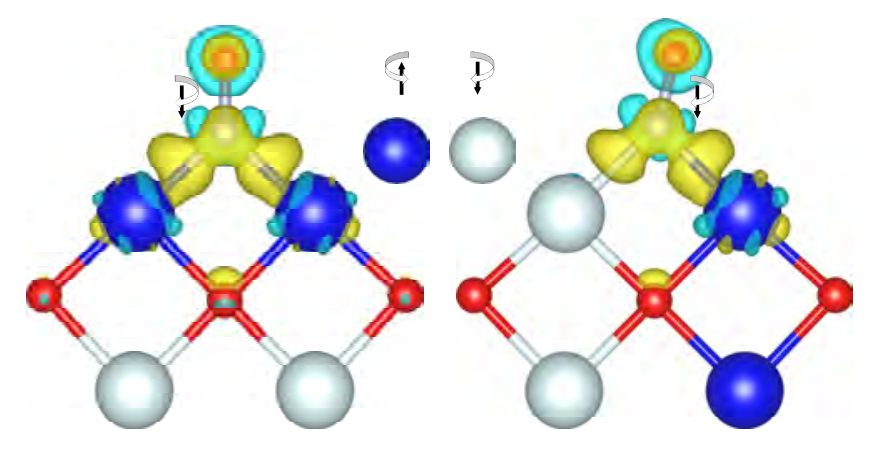


[5] H. Kuhlenbeck, S. Shaikhutdinov, H. J. Freund, Chem. Rev., 2013, 113, 3986-4034.

[6] D. P. Woodruff, Chem. Rev., 2013, 113, 3863-3886.

[7] S. M. Zhou, X. B. Miao, X. Zhao, C. Ma, Y. H. Qiu, Z. P. Hu, J. Y. Zhao, L. Shi, J. Zeng, Nat. Commun., 2016, 7, 11510.

[8] J. Suntivich, K. J. May, H. A. Gasteiger, J.B. Goodenough, Y. Shao-Horn, Science, 2011, 334, 1383-1385.

[9] S. Chretien, H. Metiu, J. Chem. Phys., 2008, 129, 074705/1074705/16.

[10] J. Behler, B. Delley, S. Lorenz, K. Reuter, M. Scheffler, Phys. Rev. Lett., 2005, 94, 036104/1-036104/4.

[11] E. Torun, C. M. Fang, G. A. de Wijs, R. A. de Groot, J. Phys. Chem. C, 2013, 117, 6353-6357.

[12] R. V. Mom, J. Cheng, M. T. M. Koper, M. Sprik, J. Phys. Chem. C, 2014, 118, 4095-4102.

[13] N. C. Tombs, H. P. Rooksby, Nature, 1950, 165, 442-443.

[14] J. S. Smart, S. Greenwald, Phys. Rev., 1951, 82, 113-114.

[15] M. Finazzi, L. Duò, F. Ciccacci, Surf. Sci. Rep., 2009, 64, 139-167.

[16] M. Finazzi, L. Duò, F. Ciccacci, in: Magnetic Properties of Antiferromagnetic Oxide Materials, Wiley-VCH, 2010, 1-23.

[17] P. W. Anderson, Phys. Rev., 1950, 79, 350-356.

[18] H. X. Deng, J. B. Li, S. S. Li, J. B. Xia, A. Walsh, S. H. Wei, Appl. Phys. Lett., 2010, 96, 162508/1-162508/3.

[19] A. Schrön, C. Rödl, F. Bechstedt, Phys. Rev. B, 2010, 82, 165109/1-165109/12.

[20] T. Archer, C. D. Pemmaraju, S. Sanvito, C. Franchini, J. He, A. Filippetti, P. Delugas, D. Puggioni, V. Fiorentini, R. Tiwari, P. Majumdar, Phys. Rev. B, 2011, 84, 115114/1-115114/14.

[21] C. G. Shull, W. A. Strauser, E. O. Wollan, Phys. Rev., 1951, 83, 333-345.

[22] U. Kaiser, A. Schwarz, R. Wiesendanger, Nature, 2007, 446, 522-525.

[23] M. Granovskij, A. Schrön, F. Bechstedt, Phys. Rev. B, 2013, 88, 184416/1-184416/5.

[24] F. Pielmeier, F. J. Giessibl, Phys. Rev. Lett., 2013, 110, 266101/1266101/5.

[25] M. Granovskij, A. Schrön, F. Bechstedt, New J. Phys., 2014, 16, 23020/1-23020/18.

[26] A. Schrön, F. Bechstedt, Phys. Rev. B, 2015, 92, 165112/1$165112 / 11$.

[27] I. Sugiyama, N. Shibata, Z. C. Wang, S. Kobayashi, T. Yamamoto, Y. Ikuhara, Nat. Nanotechnol., 2013, 8, 266-270.
[28] H. Bi, S. D. Li, Y. C. Zhang, Y. W. Du, J. Magn. Magn. Mater., 2004, 277, 363-367.

[29] V. N. Antonov, L. V. Bekenov, A. N. Yaresko, Adv. Cond. Matter Phys., 2011, 2011, 1-107.

[30] P. Thunstrom, I. Di Marco, O. Eriksson, Phys. Rev. Lett., 2012, 109, 186401/1-186401/5.

[31] L. H. Ye, R. Asahi, L. M. Peng, A. J. Freeman, J. Chem. Phys., 2012, 137, 154110/1-154110/7.

[32] H. Jiang, R. I. Gomez-Abal, P. Rinke, M. Scheffler, Phys. Rev. B, 2010, 82, 045108/1-045108/16.

[33] K. Terakura, T. Oguchi, A. R. Williams, J. Kübler, Phys. Rev. B, 1984, 30, 4734-4747.

[34] V. I. Anisimov, J. Zaanen, O. K. Andersen, Phys. Rev. B, 1991, 44, 943-954.

[35] S. L. Dudarev, G. A. Botton, S. Y. Savrasov, C. J. Humphreys, A. P. Sutton, Phys. Rev. B, 1998, 57, 1505-1509.

[36] F. Manghi, V. Boni, J. Electron. Spectrosc. Relat. Phenom., 2015, 200, 181-192.

[37] A. Rohrbach, J. Hafner, G. Kresse, Phys. Rev. B, 2004, 69, 075413/1-075413/13.

[38] A. Rohrbach, J. Hafner, Phys. Rev. B, 2005, 71, 045405/1045405/7.

[39] W. Zhao, M. Bajdich, S. Carey, A. Vojvodic, J. K. Nörskov, C. T. Campbell, ACS Catal., 2016, 6, 7377-7384.

[40] G. Kresse, J. Furthmuller, Comp. Mater. Sci., 1996, 6, 15-50.

[41] P. E. Blöchl, Phys. Rev. B, 1994, 50, 17953-17979.

[42] G. Kresse, D. Joubert, Phys. Rev. B, 1999, 59, 1758-1775.

[43] J. P. Perdew, K. Burke, M. Ernzerhof, Phys. Rev. Lett., 1996, 77, 3865-3868.

[44] S. H. Wei, A. Zunger, Phys. Rev. B, 1993, 48, 6111-6115.

[45] T. Oguchi, K. Terakura, A. R. Williams, Phys. Rev. B, 1983, 28, 6443-6452.

[46] M. Schönnenbeck, D. Cappus, J. Klinkmann, H. J. Freund, L. G. M. Petterson, P. S. Bagus, Surf. Sci., 1996, 347, 337-345.

[47] A. Zecchina, D. Scarano, S. Bordiga, G. Ricchiardi, G. Spoto, F. Geobaldo, Catal. Today, 1996, 27, 403-435.

[48] R. Wichtendahl, M. Rodriguez-Rodrigo, U. Hartel, H. Kuhlenbeck, H. J. Freund, Phys. Status Solidi A, 1999, 173, 93-100.

[49] Z. H. Zeng, J. L. F. Da Silva, H. Q. Deng, W. X. Li, Phys. Rev. B, 2009, 79, 205413/1-205413/13.

[50] Z. H. Zeng, J. L. Da Silva, W. X. Li, Phys. Chem. Chem. Phys., 2010, 12, 2459-2470.

\title{
NiO表面磁性对分子吸附的影响的第一性原理研究
}

\author{
黄传奇 ${ }^{\mathrm{a}, \mathrm{b}}$, 李微雪 $\mathrm{a}, \mathrm{b}, \mathrm{c}$, * \\ a中国科学院大连化学物理研究所催化基础国家重点实验室, 辽宁大连 116023 \\ b中国科学院大学, 北京100049 \\ c 中国科学技术大学化学与材料科学学院化学物理系, 合肥微尺度物质科学国家重点实验室(筹), 安徽合肥230026
}

摘要: 过渡金属氧化物广泛应用在当今能源与环境相关的催化领域, 理解其表面化学性质以及结构-反应活性之间的关系 对于先进催化材料的进一步发展以至理性设计至关重要. $3 d$ 后过渡系金属 $(\mathrm{Mn}, \mathrm{Fe}, \mathrm{Co}, \mathrm{Ni})$ 的氧化物以其中金属离子独特 的自旋状态和由此产生的铁磁/反铁磁性为典型特征. 研究过渡金属氧化物的自旋状态以及磁性对表面化学的影响将使我 们更加完整了解这些材料的表面化学. 以 $\mathrm{NiO}$ 为代表的后过渡系金属岩盐结构一元氧化物具有反铁磁性, 被经常作为反铁 磁研究的模型体系. 尽管在低温(低于其Neel温度)下 $\mathrm{NiO}$ 体相的完整晶体具有确定的反铁磁序, 但是一系列最新研究表明, 在条件变化时 $\mathrm{NiO}$ 表面的 $\mathrm{Ni}$ 离子可以产生不同的磁序. 以此为背景, 本工作以 $\mathrm{NiO}$ 为模型体系, 采用 $\mathrm{DFT}+\mathrm{U}$ 的第一性原理 方法研究了 $\mathrm{NiO}$ 表面磁序对表面的小分子吸附活性的影响, 包括表面吸附活性对各磁性相的表面取向以及吸附物种磁性的 依赖关系. 我们考察了 $\mathrm{NiO}$ 的5种反铁磁相和一种铁磁相, 两个晶面 $\mathrm{NiO}(001)$ 和 $\mathrm{NiO}(011)$, 顺磁性分子 $\mathrm{NO}$ 和非顺磁性分子 
CO. 我们发现表面能受磁性的影响较轻微, $\mathrm{NiO}(001)$ 面上从 49 到 $54 \mathrm{meV} / \AA^{2}, \mathrm{NiO}(011)$ 面上从 162 到 $172 \mathrm{meV} / \AA^{2}$. 在 $\mathrm{NiO}(001)$ 面上, $\mathrm{CO}$ 与 $\mathrm{NO}$ 都倾向于在 $\mathrm{Ni}$ 离子的顶位吸附. 对于不同的体相磁序与表面取向, CO吸附能的变化范围为-0.33 $-0.37 \mathrm{eV}, \mathrm{NO}$ 吸附能的变化范围为 $-0.42 \sim-0.46 \mathrm{eV}$. 在 $\mathrm{NiO}(011)$ 表面, 两种分子都倾向于吸附在由两个 $\mathrm{Ni}$ 离子构成的桥位. 我们发现相对于 $\mathrm{NiO}$ 不同磁性相的体相长程磁序, 吸附位点处构成桥位的两个 $\mathrm{Ni}$ 离子的局部磁矩相对取向对于分子的吸附 具有更加显著的影响. 计算得到 $\mathrm{NO}$ 在局部磁矩相对取向反平行 $(\uparrow \downarrow)$ 吸附位点处的吸附能为 $-0.99 \sim-1.05 \mathrm{eV}$, 在局部磁矩 相对取向平行 $(\uparrow \uparrow)$ 吸附位点处吸附会增强, 吸附能为 $-1.21 \sim-1.30 \mathrm{eV}$. 对于 CO, 尽管计算的吸附能在 $(\uparrow \downarrow)$ 吸附位点 $(-0.73 \sim$ $-0.75 \mathrm{eV})$ 与在 $(\uparrow \uparrow)$ 吸附位点 $(-0.71 \sim-0.72 \mathrm{eV}$ )非常接近, 两种吸附位点处的CO吸附时分子轨道杂化方式以及吸附后CO的 局域电子态密度却具有明显不同的特征. 本工作突出揭示了分子在过渡金属氧化物表面的多重吸附位点上吸附时吸附位 点的局域磁矩相对取向对吸附性能的影响.

关键词: 磁性; 表面取向; 分子吸附; 第一性原理; 电子结构

收稿日期: 2017-05-27. 接受日期: 2017-06-26. 出版日期: 2017-10-05.

*通讯联系人. 电话: (0551)63600650; 电子信箱: wxli70@ustc.edu.cn

基金来源: 国家自然科学基金(91645202); 国家重点研发计划(2017YFB602205); 国家重点基础研究发展计划(2013CB834603); 中国科学院前沿科学重点研究项目(QYZDJ-SSW-SLH054).

本文的英文电子版由Elsevier出版社在ScienceDirect上出版(http://www.sciencedirect.com/science/journal/18722067). 